\title{
THE NEW PRESCRIPTION DRUG PARADOX: PIPELINE PRESSURE AND RISING PRICES
}

\author{
Alice M. Ellyson \\ Anirban Basu \\ Working Paper 24387 \\ http://www.nber.org/papers/w24387 \\ NATIONAL BUREAU OF ECONOMIC RESEARCH \\ 1050 Massachusetts Avenue \\ Cambridge, MA 02138 \\ March 2018
}

The authors thank comments from seminar participants at the University of Washington PHEnOM series, Federal Trade Commission, RAND, and the Department of Defense. All opinions and errors are ours. The views expressed herein are those of the authors and do not necessarily reflect the views of the National Bureau of Economic Research.

At least one co-author has disclosed a financial relationship of potential relevance for this research. Further information is available online at http://www.nber.org/papers/w24387.ack

NBER working papers are circulated for discussion and comment purposes. They have not been peer-reviewed or been subject to the review by the NBER Board of Directors that accompanies official NBER publications.

(C) 2018 by Alice M. Ellyson and Anirban Basu. All rights reserved. Short sections of text, not to exceed two paragraphs, may be quoted without explicit permission provided that full credit, including $(\odot$ notice, is given to the source. 
The New Prescription Drug Paradox: Pipeline Pressure and Rising Prices

Alice M. Ellyson and Anirban Basu

NBER Working Paper No. 24387

March 2018

JEL No. I11,I13,I18,K23,L11,L13

\begin{abstract}
$\underline{\text { ABSTRACT }}$
Economic literature has extensively studied how prices for incumbent pharmaceutical drugs respond to generic competition after entry. However, less attention has been paid to pricing behavior in anticipation of brand-to-brand competition. We contribute to this gap in the literature by both developing a model of pricing strategies for incumbent drug manufacturers under tiered-insurance anticipating branded competition. Our model predicts rising prices for incumbent drugs for a range of elasticities as the likelihood of entry increases from competitors with horizontally-differentiated products. Using the insulin market as a natural experiment, we exploit exogenous variation in a potential entrant's completion of clinical trials to identify the effect of drug pipeline pressure on the prices of incumbent drugs. Results suggest that pipeline pressure significantly increases the prices of incumbent drugs. We expect that similar pricing effects will be prevalent with potential biosimilar entry.
\end{abstract}

\author{
Alice M. Ellyson \\ The Comparative Health Outcomes, Policy, \\ and Economics (CHOICE) Institute \\ 1959 NE Pacific St \\ Box - 357630, \\ Seattle WA 98195 \\ aellyson@uw.edu \\ Anirban Basu \\ The CHOICE Institute \\ Departments of Pharmacy, \\ Health Services, and Economics \\ University of Washington, Seattle \\ 1959 NE Pacific St., Box - 357660 \\ Seattle, WA 98195 \\ and NBER \\ basua@uw.edu
}


Several studies have recently documented rising prices for pharmaceuticals in various therapeutic areas, especially among branded drugs [Hua et al. (2016); Bennette et al. (2016); Hartung et al. (2015); Howard et al. (2015)]. Brand-name drugs account for 72 percent of drug spending, though they comprise only 10 percent of prescriptions dispensed in the U.S. [Kesselheim, Avorn and Sarpatwari (2016); Generic Pharmaceutical Association (2015); Express Scripts (2015)]. Among the most commonly used branded drugs, prices increased by about 164 percent between 2008 and 2015, greatly outpacing inflation (Office of the Assistant Secretary for Planning and Evaluation 2016). These trends are quite different from pricing trends observed in markets with generic drugs or over-the-counter drugs. Despite these considerable observed differences, the majority of our understanding in prescription drug pricing and entry relies on literature focused primarily on the competitive effects of generic drugs. The original prescription drug paradox referred to a phenomenon following generic entry whereby price-sensitive consumers switched to the generic and prices among brand name drugs subsequently rose as the remaining demand for brand name drugs was less elastic.

The new prescription drug paradox refers to a phenomenon of increasing prices corresponding with an increasing number of branded competitors. These escalating prices are perplexing given that as more treatment options become available over time, patients and insurers should have more flexibility and bargaining power in both drug choice and drug costs. Furthermore, these rising prices may be symptomatic of concerns highlighted by Dasgupta and Stiglitz (1988) that potential competition, and even competition itself, may not be sufficient to eliminate substantial market power in modern industries, especially those like healthcare and drug manufacturing where considerable Research \& Development (R\&D) is required and prices are not fully observable. In the current healthcare debate, understanding the role of competition and what it may and may not be able to accomplish is fundamental, especially in brand name competition. Therefore, there is a critical policy need to understand the role of brand name competition and potential competition to better inform policies addressing prescription drug prices.

We contribute to this policy debate by studying the effect of potential competition on pricing decisions of drug manufacturers under patent. Our analysis approaches this issue in two ways. First, we derive a model of branded pharmaceutical price competition under tiered insurance for incumbent drugs facing uncertain entry in the future. The intuition behind the model proposes that pharmaceutical firms have a long-term revenue maximizing strategy, where uncertain entry introduces a tradeoff between current revenue and future revenue. Branded drugs in the pipeline represent a kind of market exclusivity loss. Though an incumbent will be the only producer of a certain drug, other drugs which can serve as a therapeutic substitute can eat into the incumbent's market share. It may be revenue maximizing, and therefore profit maximizing, for the 
incumbent to raise prices now and offset some of the revenue loss due to market share loss if/when entry occurs. This theoretical result relies largely on the incumbent manufacturer facing less elastic demand due to insurance. The tiered structure of prescription drug coverage incentivizing the entrant to reference price the incumbent's current market prices and horizontal differentiation between drugs. The model predicts that as the credible threat of entry increases, an incumbent drug manufacturer will increase price. It also allows for an entrant with a vertically-differentiated product to price higher than existing drugs, and demonstrates that following entry, price for the incumbent will decrease, but maintain a markup.

Second, we empirically test whether existing competitors adjust price in the presence of pipeline pressure, focusing on a particular drug market without entry but with an increasing amount of potential entry insulin. This market provides a suitable natural experiment because there is no change in the composition of incumbent's over a span of several years, yet several potential entrants have new insulins in the drug development pipeline. We use clinical trial results to exploit exogenous variation in a potential entrant's success in different phases of the pipeline, and consider the change in price in quarters following pipeline shocks compared to quarters without pipeline shocks. Though the choice to start research \& development $(R \& D)$ in a particular market will be endogenous with price, neither the timing of clinical trials clearance nor regulatory approval can be controlled by market participants. Therefore, the effect of competitive pressure on prices of incumbent manufacturers can be identified using pipeline shocks. Results indicate that pipeline shocks have significant effects on the price of incumbent insulins. Pipeline pressure significantly increases the prices of incumbent drugs, and potential biosimilar entry may drive this effect. Furthermore, pipeline shocks have cumulative effects. As the probability of entry of at least one or more new branded drugs increases, the pipeline shock effect becomes stronger. Both the third and fourth pipeline shocks increase prices among incumbent drugs by about $\$ 2.30$ per shock. For the average patient taking about $12.48 \mathrm{~mL}$ of insulin per month, this corresponds to about 30 additional dollars. However, the quality of information about the shock and the particular drug shock matters. In the insulin market, rising prices due to pipeline pressure are largely driven by a branded biosimiliar in the pipeline. These results are robust to several specification checks.

\section{Background and Literature Review}

\subsection{The Drug Approval Process}

Drugs available for treatment undergo a rigorous process before they are prescribed to patients. The drug approval process begins with pre-clinical research within a manufacturing firm. If a treatment provides 
promising results from pre-clinical research, manufacturers submit an Investigational New Drug (IND) application, which is reviewed by the FDA's Center for Drug Evaluation and Research (CDER). If an IND application is approved, manufacturers begin clinical trials with people. These clinical trials are broken into three phases - Phase 1, Phase 2, and Phase 3 - where each subsequent phase indicates success in the previous phase. If all three phases of clinical trials are successful, then a manufacturer submits a New Drug Application (NDA) or Biologic License Application (BLA). The FDA reviews these applications and if a drug successfully demonstrates safety and efficacy, the drug will be approved for use in the United States. ${ }^{1}$

Drug patents and/or exclusivity awards are critical in this market. Patents are granted by the United States Patent and Trademark Office at any time, regardless of approval status, and carry a term of 20 years. Exclusivity awards place a delay and prohibitions on the approval of competitor drugs. Exclusivity takes effect once a drug receives FDA approval, with the longest possible exclusivity award, 7 years, applying to orphan drugs. According to the FDA, "patents and exclusivity may or may not run concurrently and may or may not cover the same aspects of the drug product." ${ }^{2}$ Yet, both of these institutional awards grant a drug manufacturer monopoly power, which provides the incentives for pharmaceutical companies to invest in $\mathrm{R} \& \mathrm{D}$ for innovative treatments. Recent estimates of $\mathrm{R} \& \mathrm{D}$ costs per drug approval amount to about $\$ 2.87$ billion (DiMasi, Grabowski and Hansen 2016), so these awards are critical to incentivize these incredibly risky investments. Most work studying the effect of entry on pharmaceutical prices focuses on generic entry. Generic drugs are pharmacologically-identical to their brand-name counterpart drugs. They have the same intended use, effects, side-effects, administration route, risks, safety, and dosage as the original drug. Drugs manufacturers are protected from generic competition during patent/exclusivity periods. When the period granted ends, a pharmaceutical product may face generic entry. However, drugs under the patent and/or exclusivity period may face competition from other patented drugs which obtain the same or similar therapeutic goal, but are not pharmacologically-identical to existing drugs, and therefore do not violate patent and/or exclusivity rules.

We will refer to this type of competition as brand-to-brand, brand-name, or branded competition. Note that in branded competition, it is possible to have both horizontally-differentiated and verticallydifferentiated products. Horizontally-differentiated drugs are different, but the choice of which drug depends on the consumers preferences. Vertically-differentiated drugs are of different quality. Inn other words, drugs are different and all consumers would prefer one drug over the other. The patent process does not require

\footnotetext{
${ }^{1}$ More information on this process can be reviewed at https://www.fda.gov/Drugs/DevelopmentApprovalProcess/SmallBusinessAssistance/ucm053131.htm

${ }^{2}$ More information on drug patents and exclusivity can be found at https://www.fda.gov/Drugs/DevelopmentApprovalProcess/ucm079031.htm
} 
that new drugs be vertically-differentiated. Manufacturers seeking FDA approval are only required to show that the drug's benefits outweigh its known risks and that the drug can be manufactured in a way that ensures its quality. Drugs are not required to show that they perform "better" than existing drugs on the market. Patents are awarded as long as the new drug has a formulation that is different from existing drugs. Therefore, it is possible to observe both vertical differentiation and/or horizontal differentiation in branded competition. "Me-too drugs" may be considered horizontally-differentiated drugs.

The amount of brand-to-brand competition an incumbent may face is considerably more uncertain than the threat of generic entry. Studies report that the clinical success rate - the product of individual phase transition probabilities for the clinical trials portion of drug development - is quite low, around one in ten (Hay et al. 2014). However, estimates from various studies indicate that success in phase 3 ranges from 55 to 64 percent [Abrantes-Metz, Adams and Metz (2004); Kola and Landis (2004); DiMasi et al. (2010); Hay et al. (2014)]. Thus, the credibility of the threat of entry increases considerably once a drug reaches phase 3. These studies also suggest that phase 3 success further increases the threat of entry. Estimates from the same set of studies indicate that between 77 - 93 percent that successfully complete phase 3 studies move on to NDA submission and approval.

\subsection{Drug Price Competition}

The economic field of industrial organization has extensively studied the game theoretic behavior of firms and how incumbent firms anticipate and respond to entry (Tirole 1988). Theoretical work largely demonstrates that under many circumstances entry - and even potential entry (Baumol, Panzar and Willig 1982) can drive markets to the efficient allocation of resources. In many ways, competition has generally been regarded as a force which exerts "downward pressure on costs, reduces slack, provides incentives for the efficient organization of production, and even drives innovation forward" (Nickell 1996). It has also been largely regarded as a force to reduce price. Yet, theoretical work also suggests that there are a wide array of anticompetitive strategies a firm can employ to deter entry (Salop 1979). This prompted a series of econometric studies investigating the market effects of entry in various industries [Bresnahan and Reiss (1991); Berry (1992); Bunch and Smiley (1992); Mazzeo (2002); Pakes, Ostrovsky and Berry (2007); Aghion et al. (2009)]. The empirical work indicates that the incumbent response to entry is both mixed and selective (Geroski 1995).

This econometric work has important implications for the prescription drug pricing debate. It is not clear that competition, potential or actual, can be the silver bullet to the drug pricing dilemma. Research 
following the passage of the 1984 Drug Price Competition and Patent Term Restoration Act indicated that generic competition was a driving effect in declining prices [Grabowski and Vernon (1992); Frank and Salkever (1997); Morton (1999); and Reiffen and Ward (2005)], with a minor caveat that market size and concentration may limit the speed and extent of the transition to lower priced generics (Tenn and Wendling 2014). Yet, this research also suggests that competition is not the only market incentive at play. Grabowski and Vernon (1992), Frank and Salkever (1997), and Ching (2010) all contend that there is considerable consumer heterogeneity in price-sensitivity which can produce differential effects on drug prices following entry. Ching (2010) also suggests consumers learning plays a role and incumbent manufacturers have an incentive to slowly raise prices, retaining as much market share as possible and slowing the learning process about new drugs.

Furthermore, research has indicated a variety of factors influence the price of prescription drugs, mostly factors that may mitigate the pressure from competition. Drug-level factors like innovation, the development of drugs with therapeutic gains from greater efficacy and/or safety relative to existing drugs [Reekie (1978) and $\mathrm{Lu}$ and Comanor (1998)], differentiation, both vertical and horizontal, and advertising increase drug prices [Perloff, Suslow and Seguin (1995); Bhattacharya and Vogt (2003); Ching (2010)]. Institutional-level factors like regulatory standards, patent protection, and market structure can also influence market efficiency and price dynamics [Danzon and Chao (2000); Kyle (2007); Brekke, Canta and Staume (2016)]. Additionally, the role of insurance as an institutional factor in drug pricing has largely been assumed away, despite a key detail that nearly all prescription drugs are provided through health insurance plans. Nearly all Americans obtaining health coverage through an employer have access to a plan with prescription drug coverage, and in most cases the worker has coverage without first meeting a deductible (Claxton et al. 2016). In addition, over $89 \%$ of these plans have tiered prescription drug coverage (Claxton et al. 2016). It is clear that prescription drug insurance will tie into consumer price-sensitivity [Lakdawalla and Sood (2009) and Berndt, McGuire and Newhouse (2011)].

We suspect that typical prescription drug insurance plans largely eliminate patient price-sensitivity resulting in a lack of downward pressure on price. Specifically, we conjecture that under this institutional structure, both incumbent drug manufacturers and potential entrants face a pricing decision under which increasing price is the dominant strategy. We contribute to the existing literature on anticipating entry and pharmaceutical competition in the following ways. First, we explore the effect of pressure in the pipeline on prescription drugs. The aforementioned econometric work has focused on the effects of actual entry, because it is not often possible to observe potential entry. However, in the case of pharmaceuticals, information from 
the drug development pipeline is publicly available due to the Food and Drug Administration Modernization Act (FDAMA) of 1997 requiring trial registry. Therefore, we can directly observe potential competitors in the pipeline and identify the effect of the credible threat of entry on incumbent pricing strategies. Second, we develop a two-period model of pricing strategies under tiered prescription drug insurance for an incumbent drug manufacturer. The model predicts rising prices for incumbent drugs for a range of elasticities as the likelihood of entry increases. Third, we econometrically assess pricing adjustments due to pipeline pressure, using the insulin market as a natural experiment. Finally and perhaps most importantly, we contribute to the growing assessments of pharmaceutical competition. Policy-makers may expect entry and competition to improve consumer welfare, but we find evidence that this wishful thinking is unlikely to be true.

\subsection{A Motivating Example: Insulin}

Insulin is a life-saving drug used to treat diabetes. ${ }^{3}$ It helps patients maintain glycemic control and prevent and/or delay considerable complications and costs. On average, medical expenditures in the US are approximately 2.3 times higher for patients with diabetes than those without, and it accounts for more than 1 in 5 health care dollars spent (Yang et al. 2013). Therefore, consistent treatment with insulin can be both beneficial to patients and the US healthcare system. This particular drug is a biologic, originally discovered and patented in the early 1920s, marking a monumental improvement in treating patients with diabetes. In the last 95 years, incremental improvements in safety, efficacy, and convenience have characterized the market for insulin. Older versions of insulin were derived from animal and human DNA. The newest version of insulin which is derived from recombinant DNA (rDNA), the insulin analogue, was introduced on the U.S. market in 1996. Animal and human insulins are considered somewhat inferior in both efficacy and safety to insulin analogues, ${ }^{4}$ and used less frequently.

Recent research reports that the price of insulin has soared in the previous decade. Hua et al. (2016) report that the price of insulin, measured as the mean price per milliliter, rose 197 percent from 2002 to 2013. Between 2007 and 2014, there were no new insulin analogues approved by regulatory agencies, but there were several in pipeline development. Various insulins in drug development completed the final phase of clinical trials and submitted national drug applications (NDAs) in the following quarters: 2009q1, 2011q3, 2013q4, 2014q2. Despite the rising threat of potential competition, Figure 1 depicts that the average inflation-adjusted price of insulin per $\mathrm{mL}$ is increasing over time, from $\$ 14.67$ at the beginning of 2007 to

\footnotetext{
${ }^{3}$ It is the only treatment for type 1 diabetes, and is used as a second and/or third line therapy for type 2 diabetes when other treatments are unsuccessful.

${ }^{4}$ Insulin analogues both improved glycemic control and reduced the rate of adverse events in the form of severe hypoglycemia, two life-threatening issues for patients with this condition, compared to earlier versions of insulin like animal and human.
} 


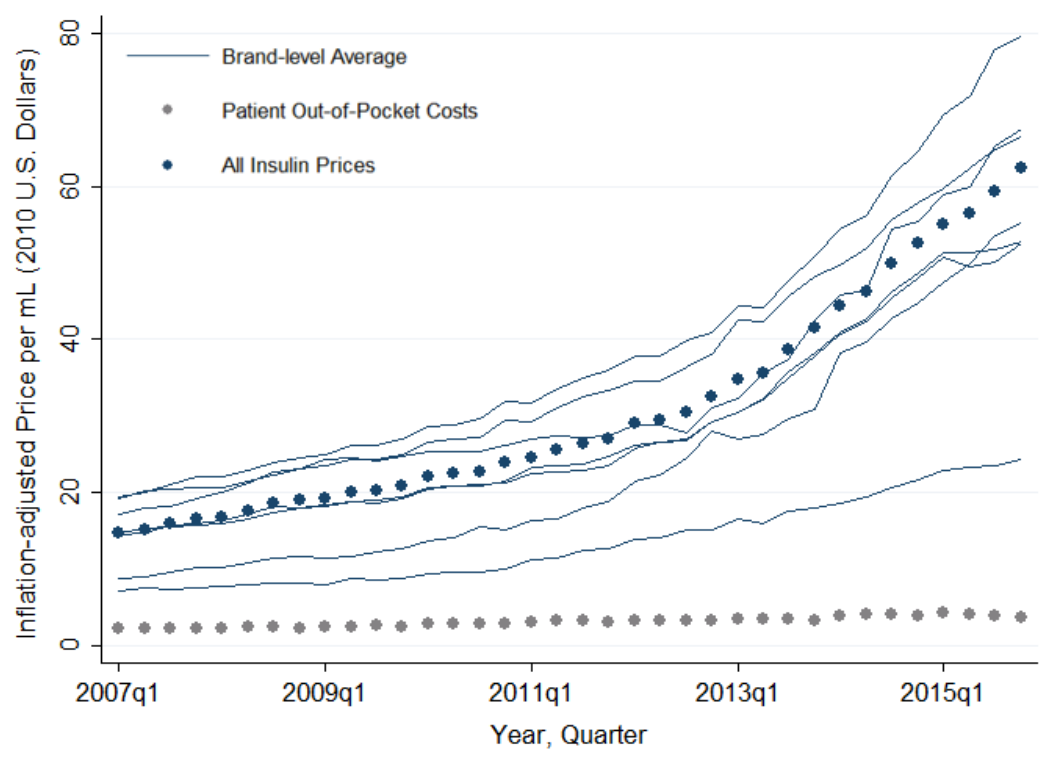

Figure 1: Average Prices for all Insulin Prescriptions, 2007-2015

$\$ 61.22$ by the end of 2015 . On average, this is a 317.3 percent increase in the price of incumbent insulins. The majority of these price increases were absorbed by payers, though this could be dampened by the size of rebates. Payments made by patients increased by 56 percent.

\section{Brand Name Drug Competition with Uncertain Entry}

Consider a drug manufacturer in a two-period model facing uncertain entry in the second period. In the first period, the drug manufacturer is a monopolist. This drug is a brand name drug under patent. Entry in the second period is probabilistic. Therefore, the monopolist is referred to as the "incumbent" and a new "entrant" firm may enter the market. If entry occurs, the entrant firm produces a branded drug which is qualitatively similar to the incumbent's product but considered to be an imperfect substitute. This is because, the entrant's drug may have limited information on effectiveness at regulatory approval, while patients requiring treatment for this drug have experience with the incumbent's drug for consumers. Therefore, the differentiation between the incumbent's and the entrant's drug is horizontal and driven by patient preferences, doctor preferences, or some other implicit preference to try the new treatment. After observing price in the first period, there is some probability that entry occurs and both the incumbent and entrant simultaneously set a price in the second period.

In the presence of insurance, the demand price faced by the consumer is vastly different from the market 
price that a monopoly may set. In fact, in many cases an insurer would only charge a fixed copay from the beneficiaries for a drug. The insurer pays the rest of the price. Berndt, McGuire and Newhouse (2011) demonstrate that coinsurance makes demand less elastic and suggest that plans with fixed copayments will result in even higher prices with price increases translated into higher premiums. Consequently, consumer demand for this drug is inelastic, giving the monopolist an opportunity to set a price that can extract rents from the market. This is unlike a traditional monopolist whose price is constrained directly by the elasticity of consumers. The final price set by the monopolist would involve negotiations with the insurer so that the price would preserve a non-negative profit margin for the insurer. For our purposes, we do not need to explicitly consider the specific form of insurer constraint. Whatever it is, we acknowledge that it is used to set equilibrium prices. Furthermore, we acknowledge that the presence of uncertainty, imperfect information, and insurance can have a significant effect on markets as demonstrated by Rothschild and Stiglitz (1976) and Arrow (1963). Without modeling these details, this model attempts to outline the incentives for a drug manufacturer whose demand is largely supplied by insurance. Our goal is to see if the equilibrium price prior to entry is influenced by other factors, especially pressure from the drug development pipeline, or potential competition.

\subsection{Extensive Form of the Two Period Model}

There are two participants, the incumbent and the entrant. In the first period, the incumbent chooses price. In the second period, both the entrant and the incumbent make a simultaneous choice on price. The incumbent has complete but imperfect information about the likelihood of entry in the second period. Let subscript $i$ represent the incumbent firm and subscript $e$ denote the entrant firm. In addition, let subscript 1,2 denote the period of the game. Then, for example, term $R_{i}$ is the incumbent's revenue, and $P_{1 i}, c_{1 i}$, and $Q_{1 i}$ denote the incumbent's price, copayment, and quantity in the first period, respectively. There are three formal assumptions that are required.

Assumption 1. Each product in the market is available to consumers at a constant demand price (for example, a set copay) via insurance.

Assumption 2. Without loss of generality, marginal costs are zero for each drug.

Assumption 3. Drugs are homogenous in terms of clinical benefit. That is, they are therapeutically equivalent in treatment, but may exhibit other quality attributes that are more or less desirable according to patient preferences. 
Assumption 4. Under tiered prescription drug insurance, a lower price generates a more favorable tier placement, and therefore a lower copay charged. That is, if the entrant sets a price $P_{e}=\gamma P_{i}$ where $\gamma \leq 1$, and the copayment is a function of the fraction of price charged, $c_{e}=c_{e}(\gamma)$, copayments can be anchored at $c_{e}(0)=0$ and $c_{e}(1)=c_{i}$ where setting price equivalent to the incumbent dictates that the two drugs be placed on the same insurance tier. It follows that the elasticity of copayment with respect to price is linear, $\frac{\partial c i}{\partial P_{i}}=\frac{c_{i}}{P_{i}}$ and $\frac{\partial c_{e}}{\partial P_{e}}=\frac{c_{e}}{P_{e}}$ in both periods.

In what follows, we solve for a Sub-game Perfect Nash Equilibrium (SPNE) using backward induction (Selton 1965) and the aforementioned Assumptions. Therefore, we will first find best response functions, the optimal strategy for a particular player given the strategies of other players, for both players in the second period, and use these expectations to examine the pricing strategy for the incumbent in the first period.

\subsection{Equilibrium Strategy for the Entrant}

First, consider the equilibrium strategy for the entrant. Let price set by the entrant be $P_{2 e}=\gamma P_{2 i}$ where $\gamma \leq 1$ and denotes the fraction the entrant sets its price in reference to $P_{2 i}$. Let $c_{2 e}=c_{2 e}(\gamma)$ where $c_{2 e}$ denotes the copayment that the insurer charges for the entrant's drug in the second period. Naturally, $c_{2 e}(\gamma) \leq c_{2 i} \forall \gamma$ and $c_{2 e}^{\prime}=\frac{\partial c_{2 e}}{\partial \gamma}>0$, that is, a lower price of the entrant's product would lead to the lower copay charged. Let $c_{2 e}(\gamma)$ be linear in $\gamma$. Since $c_{2 e}(0)=0$ and $c_{2 e}(1)=c_{2 i}$, then $c_{2 e}^{\prime}=c_{2 i}$. It follows that for both the incumbent and the entrant, the elasticity of copayment with respect to price is 1 , that is, $\frac{\partial c i}{\partial P_{i}}=\frac{c_{i}}{P_{i}}$ and $\frac{\partial c_{e}}{\partial P_{e}}=\frac{c_{e}}{P_{e}}$ in both periods. In the second period, if a new manufacturer gets regulatory approval to enter the market with a qualitatively similar but imperfect substitute to the incumbent's drug, the pricing decision follows a simultaneous game where the incumbent and the entrant are trying to price their own products anticipating competition from the other, albeit in the presence of insurance. Like the incumbent, the entrant is also subject to the demand price separation due to insurance that protects it from the full price-elasticity of consumer demand. Let the demand function for the entrant be given as

$$
Q_{2 e}=a-b_{1} c_{2 e}+b_{2} c_{2 i}
$$

where $c_{2 e}$ and $c_{2 i}$ are the copayments set for the entrant's and incumbent's drugs, respectively, by the insurer. Here $b_{1}$ captures the responsiveness of the entrant's demand with respect to its own copayment, while $b_{2}$ captures the responsiveness with respect to the incumbent's copayment. $a$ denotes the demand intercept facing the entrant. 
If the insurer covers both drugs at the same copayment level (i.e. $c_{2 e}=c_{2 i}$ ), and there are no restrictions set on which drug the patient chooses to take, switching to the entrant's drug is determined entirely by patient preferences, doctor preferences, or some other implicit preference to try the new treatment. Both the incumbent and entrant drug can achieve the same treatment goal, but rather switching to the new drug is determined by underlying preferences. Gaynor, Propper and Seiler (2016) and Santos, Gravelle and Propper (2017) demonstrate that certain quality characteristics matter in this type of discrete choice between products and/or providers in healthcare, specifically considering patient choice among hospitals in the English National Health Service. As previously mentioned, we assume that products in this theoretical model are horizontally differentiated, so that switching to the new drug is not driven by vertical differences in quality. Let there be some portion, $\theta$, of the population demanding treatment for this condition, $Q$, at a copay of $c_{2 i}$ who will switch to the entrant's drug under these conditions, leaving a fraction $(1-\theta)$ for the incumbent's demand. Therefore, following a linear inverse demand function for the entrant's drug under this condition is

$$
Q_{2 e}=\theta Q=a-b_{1} c_{2 i}+b_{2} c_{2 i} \Longrightarrow a=\theta Q+c_{2 i}\left(b_{1}-b_{2}\right)
$$

Under such a scenario, there is no reason for the entrant to price its drug any differently than the current prevalent price of the monopolist, i.e. $P_{2 e}=P_{2 i}$. This is because $P_{2 i}$ is the maximum price the entrant can charge in this simultaneous game, which maximizes its revenues since $\theta Q$ is outside of entrant control.

However, since insurers often utilize a tiered system of copays to induce price elasticity of demand between two products, the entrant will have a pricing decision at hand. Specifically, the entrant debates whether to charge a lower price than $P_{1 i}$ so that its product may be placed in a higher tier, (i.e. lower copayment) than the monopolist incumbent's product. Would the demand surge due to this favorable placement be enough to overcome the shortfall in revenue due to the lower price? To answer this question, we solve the entrant's revenue maximization problem as follows. The entrant will maximize revenue in the second period, which also maximizes profit. This is given by

$$
\max _{P_{2 e}} R_{e}=P_{2 e} \cdot Q_{2 e}
$$

Substituting for $Q_{2 e}$ using Equation 2, we can rewrite the entrant's second-period problem as

$$
\max R_{e}=P_{2 e} \cdot Q_{2 e}=P_{2 e}\left[a-b_{1} c_{2 e}+b_{2} c_{2 i}\right]
$$

Solving the entrant's first-order condition with respect to $P_{2 e}$, setting this equal to zero, and solving for 
$P_{2 e}$ generates the best response function for the entrant. The best response function describes the optimal strategy for a particular player, here the entrant, given the strategies of other players, here the incumbent. To simplify the entrant's best response function, we apply Assumption 4 and Equation 2 as well as requiring that $\frac{c_{2 e}}{P_{2 e}}=\frac{c_{1 i}}{P_{1 i}}$ and $\frac{c_{2 i}}{P_{2 i}}=\frac{c_{1 i}}{P_{1 i}}$.

$$
P_{2 e}=\frac{\theta Q P_{1 i}}{2 b_{1} c_{1 i}}+\frac{1}{2} P_{2 i}
$$

Equation 4 displays the entrant's best response function. Note that if $\theta=0$, that is, no one switches to the entrant's drug, the entrant prices the new drug at half the incumbent's price. Notice also that this suggests the entrant may increase price over the incumbent's drug, if the market share gain is high relative to the elasticity with respect to copay. In fact, if the entrant's product is substantially differentiated vertically, and therefore the entrant captures a larger share of demand, the entrant may price considerably higher than the incumbent price.

\subsection{Equilibrium Strategy for the Incumbent}

The incumbent two-period decision problem is given as

$$
\max _{P_{1 i}, P_{2 i}} R_{i}=P_{1 i} \cdot Q_{1 i}+E\left(R_{2 i}\right)
$$

where $P, Q$, and $R$ denote price, quantity, and revenue, respectively. In drug manufacturing, fixed costs are high and sunk, and marginal costs of production are low. Therefore, by Assumption 2, maximizing revenue is equivalent to maximizing profit. Note that although the monopolist can set prices with certainty in the first period and thereby determine revenue, it faces uncertainty about the second period stream of revenue due to the potential entry of the entrant's product. Let the probability of an entrant entering the market in period 2 be denote by $\rho$. Hence the incumbent's problem can be written as:

$$
\max R_{i}=P_{1 i} \cdot Q_{1 i}+\left[(1-\rho) P_{1 i} \cdot Q_{1 i}+\rho P_{2 i} \cdot Q_{2 i}\right]
$$

We can also find a best response function for the incumbent in the second period based on the entrant's best response. Like the entrant, the incumbent also faces demand separation. Let the inverse demand function for the incumbent in the second period be given as

$$
Q_{2 i}=\alpha-\beta_{1} c_{2 i}+\beta_{2} c_{2 e}
$$


From the demand function of the entrant, we know that if the copayments for both products are the same, there is a shift of demand of $\theta Q$ from the incumbent to the entrant for reasons other than demand prices. By construction, this also means that there is no brand loyalty strategy that can alter the size of $\theta$. Therefore, at equal copay, (7) can be written as:

$$
Q_{2 i}=(1-\theta) Q=\alpha-\beta_{1} c_{2 i}+\beta_{2} c_{2 e} \Longrightarrow \alpha=(1-\theta) Q+c_{2 i}\left(\beta_{1}-\beta_{2}\right)
$$

Next, we will find the incumbent's best response function in the second period, using the entrant's best response function. Since we are seeking an SPNE using backward induction, we must consider the incumbent's second period decision. The incumbent will maximize revenue in the second period given by

$$
\max P_{2 i} \cdot Q_{2 i}=P_{2 i} \cdot\left[\alpha-\beta_{1} c_{2 i}+\beta_{2} c_{2 e}\right]
$$

By simplifying using the entrant's best response function from Equation 4 as well as $\frac{c_{2 e}}{P_{2 e}}=\frac{c_{1 i}}{P_{1 i}}$ and $\frac{c_{2 i}}{P_{2 i}}=\frac{c_{1 i}}{P_{1 i}}$, we can describe the incumbent's second period maximization problem only in terms of incumbent's prices. This is given by

$$
\max P_{2 i} \cdot Q_{2 i}=P_{2 i} \cdot\left[\alpha-\beta_{1} \frac{c_{1 i}}{P_{1 i}} P_{2 i}+\beta_{2} \frac{c_{1 i}}{P_{1 i}}\left(\frac{\theta Q P_{1 i}}{2 b_{1} c_{1 i}}+\frac{1}{2} P_{2 i}\right)\right]
$$

Taking the incumbent's first-order condition with respect to $P_{2 i}$ and solving for $P_{2 i}$ in terms of $P_{1 i}$ gives

$$
P_{2 i}=P_{1 i} \frac{\alpha+\beta_{2} \frac{\theta Q}{2 b_{1}}}{c_{1 i}\left(2 \beta_{1}-\beta_{2}\right)}
$$

Equation 11 describes the incumbent's best response function.

Theorem 1. Under Equations 4 and 11, the incumbent will raise its market price in period 1 if the probability of an entrant entering the market in period 2 increases, i.e. $\frac{d P_{1 i}}{d \rho}>0$.

Recall the incumbent's problem in Equation (6),

$$
\max R_{i}=P_{1 i} \cdot Q_{1 i}+\left[(1-\rho) P_{1 i} \cdot Q_{1 i}+\rho P_{2 i} \cdot Q_{2 i}\right]
$$

Replacing $Q_{2 i}$ using Equation 7 and replacing $Q_{1 i}$ assuming that $Q_{1 i}=Q$, i.e. the incumbent was meeting the full demand in period 1 at the copay of $c_{2 i}$. Furthermore, the inverse demand function for the incumbent in the first period is $Q_{1 i}=\alpha-\beta_{1} \cdot c_{1 i}$, where the elasticity of copayment with respect to price is 1 (following 
Assumption 4), i.e. $\frac{\partial c_{1 i}}{\partial P_{1 i}}=\frac{c_{1 i}}{P_{1 i}}$. To simplify expressions, let $\omega=\frac{\alpha+\beta_{2} \frac{\theta Q}{2 b_{1}}}{2 \beta_{1}-\beta_{2}} \Longrightarrow \quad P_{2 i}=\omega \frac{P_{1 i}}{c_{1 i}}$. After simplification presented fully in the Appendix, we can rewrite the incumbent's problem in (12) as

$$
\max _{P_{1 i}} R_{i}=P_{1 i} \cdot\left(\alpha-\beta_{1} \cdot c_{1 i}\right)+(1-\rho) P_{1 i} \cdot\left(\alpha-\beta_{1} \cdot c_{1 i}\right)+\rho \omega \frac{P_{1 i}}{c_{1 i}}\left(\alpha-\beta_{1} \omega+\beta_{2}\left[\frac{\theta Q}{2 b_{1}}+\frac{1}{2} \omega\right]\right)
$$

Next, we differentiate the incumbent's revenue with respect to price and set this equal to zero yields the incumbent's first-order condition with respect to $P_{1 i}$. After simplifying this expression, we have

$$
2 \alpha-4 \beta_{1} c_{1 i}-\alpha \rho+\rho 2 \beta_{1} c_{1 i}=0
$$

This condition is based on both the entrant and the incumbent choosing optimal strategies according to the SPNE. We are not necessarily concerned with the equilibrium, but rather how equilibrium pricing in the first period changes as the probability of entry changes. In other words, when $\frac{d P_{1 i}}{d \rho} \geq 0$, the incumbent will increase price in the first-period as the probability of entry increases. To assess this, we use implicit function differentiation. Therefore, the incumbent will raise first-period price as long as the following inequality is true.

$$
\frac{\mathrm{d} P_{1 i}}{\mathrm{~d} \rho}=\frac{2 \beta_{1} \frac{c_{1 i}}{P_{1 i}}(\rho-2)}{2 \beta_{1} c_{1 i}-\alpha} \geq 0
$$

What conditions are required to observe this effect? Note that by definition $0<\rho<1$, and $2 \beta_{1} \frac{c_{1 i}}{P_{1 i}}>0$, so the numerator will be negative. Therefore, we must find conditions under which the denominator is also negative, or when $2 \beta_{1} c_{1 i}-\alpha<0$. Recall that demand facing the incumbent in the first period is $Q_{1 i}=\alpha-\beta_{1} \cdot c_{1 i}$. Elasticity for this demand curve is given by

$$
\varepsilon=\frac{\partial Q}{\partial P} \cdot \frac{P}{Q}=-\beta_{1} \frac{c_{1 i}}{P_{1 i}} \cdot \frac{P_{1 i}}{Q_{1 i}}=-\beta_{1} \frac{c_{1 i}}{Q_{1 i}} \Longrightarrow \varepsilon=\frac{-\beta_{1} c_{1 i}}{\alpha-\beta_{1} c_{1 i}} \Longrightarrow|\varepsilon|=\frac{\beta_{1} c_{1 i}}{\alpha-\beta_{1} c_{1 i}}
$$

For what elasticity will $2 \beta_{1} c_{1 i}-\alpha<0$ be true? Suppose elasticity for prescription drugs is 0.20 as indicated 
in the RAND Health Insurance Experiment. Then,

$$
\begin{gathered}
\varepsilon=\frac{\beta_{1} c_{1 i}}{\alpha-\beta_{1} c_{1 i}}<0.2 \\
\beta_{1} c_{1 i}<0.2\left(\alpha-\beta_{1} c_{1 i}\right) \\
\beta_{1} c_{1 i}+0.2 \beta_{1} c_{1 i}<0.2 \alpha \\
\beta_{1} c_{1 i}-\frac{1}{6} \alpha<0 \\
2 \beta_{1} c_{1 i}-\frac{1}{3} \alpha<0
\end{gathered}
$$

As long as $\alpha>1,2 \beta_{1} c_{1 i}-\frac{1}{3} \alpha<0 \Longrightarrow 2 \beta_{1} c_{1 i}-\alpha<0$. Since $\alpha$ is a demand intercept, this is almost certainly the case. Therefore, the incumbent will increase price in the first period as the probability of entry is increasing. In fact, we can verify that this condition will be satisfied as long as $|\varepsilon| \leq 1$. Many prescription drugs face relatively inelastic demand, especially those that are life-saving. Therefore, this range of elasticity is likely to be satisfied, especially in the market we consider empirically. In what follows, we consider the price effects of pipeline pressure in a particular drug market, insulin.

\section{Empirical Strategy: Pipeline Pressure in the Insulin Market}

News of potential competition in the pipeline becomes available as entrants clear various phases of drug development and publish the results from clinical trials. As each phase of development is cleared, the likelihood of competing with at least one entrant increases, and incumbent firms may adjust their expectations about future competition. This news from the pipeline serves as an exogenous shock to the existing market. The completion of potential entrant clinical trials determine the timing of these shocks, not existing competitors. Therefore, news of potential entry will be regressed on the prices of existing insulin drugs. We model price as

$$
P_{i t}=\alpha_{i}+\theta_{1} t+\theta_{2} t^{2}+\mathbf{Q t r}_{2,3,4} \boldsymbol{\eta}+\mathbf{X}_{i t} \boldsymbol{\beta}+\text { PipelineShocks }_{i t} \boldsymbol{\delta}+u_{i t}
$$

where $P_{i t}$ is the price of drug $i$ in quarter $t$, defined as average (median) payments for one mL supply. $\alpha_{i}$ are drug-level fixed effects which control for time-constant drug characteristics. This can include product differentiation, like higher concentration insulins, characteristics that affect ease of use, and therapeutic gains over existing drugs. $t$ denotes time since the first phase 3 clearance of a potential competitor and captures continuous trends in price. $\mathbf{Q t r}_{2,3,4}$ is equal to one in the second, third, and fourth quarters, respectively, of 


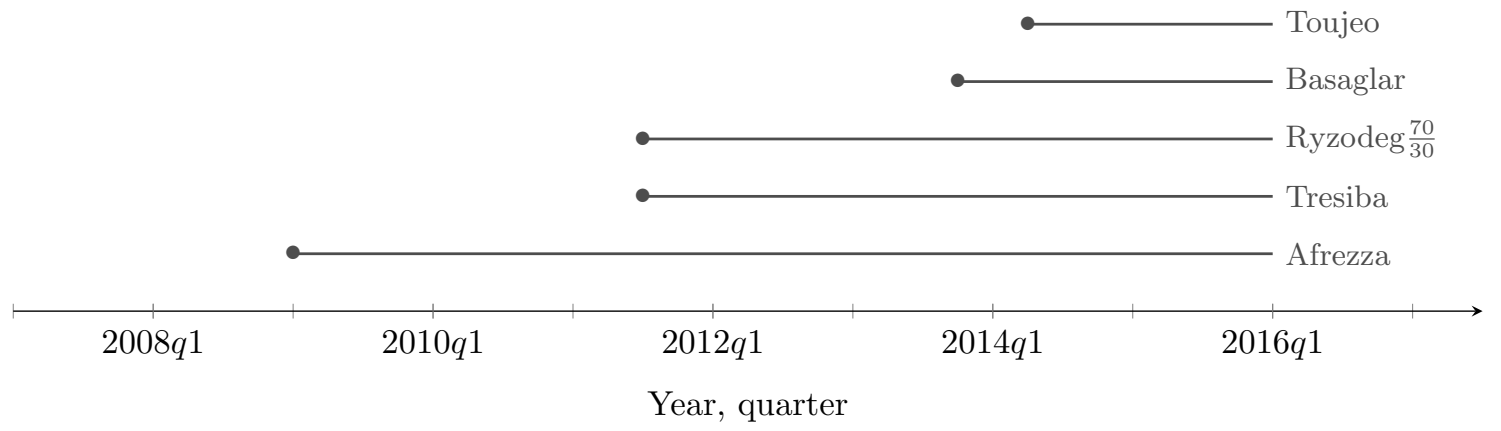

Figure 2: Pipeline Shocks, Completion of Phase 3 of Drug Development

the year which capture yearly cyclical trends in price. $\mathbf{X}_{i t}$ includes market characteristics like the number of quarters the drug was on the market at baseline, and the health plan type providing coverage. Length of time on the market may also impact the pricing decision. More established brands may feel less pressure if they have had an ample amount of time to build brand loyalty to their product. Bhattacharya and Vogt (2003) establish this strategy, intended on increasing market share and improving brand loyalty to the drug, prior to generic entry. $u_{i t}$ is the idiosyncratic error, assumed to be independently and identically distributed.

Finally, PipelineShocks ${ }_{i t}$ is the main factor of interest in this analysis and represents exogenous shocks from the drug development pipeline. In the initial specification, we consider the strongest signal of potential entry, completion of phase 3 clinical trials. We use the first national drug application (NDA) submission to mark successful completion of phase 3 trials. ${ }^{5}$ PipelineShocks $s_{i t}$ is a vector of a series of indicators which mark each additional completion of Phase 3 by a new potential entrant. ${ }^{6}$ Table 8 in the Appendix lists all the clinical trials on record for insulins in the clinical trials phase of development during our panel. Figure 2 depicts how the PipelineShocks ${ }_{i t}$ indicators are constructed for Phase 3 using information from Table 8. Once a drug in development clears a particular phase, a new indicator is created and the indicator stays on, i.e. is equal to one, for the remainder of the panel. Note that in some cases, information about more than one drug in the pipeline comes out at the same time. Therefore, this information will be represented jointly by one indicator, since separate effects cannot be estimated.

\footnotetext{
${ }^{5}$ Both Tresiba and Ryzodeg $\frac{70}{30}$ have an intial NDA submission, which is resubmitted in the first quarter of 2015. Existing drug manufacturers will likely internalize the information from the initial NDA submission in their price setting strategy, so the subsequent submission is not considered.

${ }^{6}$ In other specifications, we also consider the informational shocks from Phase 1 and Phase 2.
} 


\section{Data}

Data on insulin prices was obtained from Truven Marketscan Commercial and Medicare Claims from 20072015. This resource includes individual-specific healthcare enrollment, utilization, and expenditure data from inpatient, outpatient, prescription drug, and carve-out services. MarketScan databases include both commercial claims, and medicaid and medicare supplements. All claims from Truven Marketscan from January 1, 2007 to December 31, 2015 with national drug codes (NDC) for all types of insulin were included in this analysis. These NDCs are listed in Table 9 in the Appendix. Claims were included for all enrollees regardless of age, insurance type, or diabetes type (diagnosis codes). We excluded claims where the enrollee identification number was missing (less than one percent of claims), and claims that were not fully adjudicated (less than 1.3 percent of claims). ${ }^{7}$ In addition, claims for other anti-hyperglycemic medications were not included in this analysis. ${ }^{8}$ After implementing these criterion on all insulin claims, there are $28,801,450$ claims. The vast majority of claims (28,388,234 claims or 98.56 percent of claims) are for incumbent drugs, whose prices are considered in the analysis. In total, 87.2 percent of claims are for insulin analogues, the most modern form of insulin.

The price, the main outcome of interest, was calculated as total expenditures per patient for a one mililiter $(\mathrm{mL})$ supply of each drug in each quarter adjusted for inflation using the urban consumer price index (CPI). Expenditures include payments from patients (copayments and coinsurance) and payments from the health plan. Health plan payments reflect a reduced payment after discounts are applied, but before rebates are transferred. Patient prices for a thirty-day, one $\mathrm{mL}$ supply were also computed. These patient prices include both copayments and coinsurance, depending on the construction of the health plan. In most cases, only a copayment or coinsurance is required. Figure 3 depicts the distribution of insulin price. Prices are considerably positively skewed with a long tail on the right hand side. However, over 95.9 percent of prices are concentrated between 0 and 100. Sensitivity checks were conducted to determine whether this significantly changes the results we obtain.

The following graphics derived from insulin claims are informative. Figure 4 depicts the frequency of claims for insulin by health plan type. ${ }^{9}$ The majority of claims, 56.94 percent, are provided by PPO plans.

\footnotetext{
${ }^{7}$ When a claim does not match on all required criteria, adjustments cannot be made. This is a very small portion of the sample.

${ }^{8}$ These drugs are not typically used to treat patients with type 1 diabetes and among patients with type 2 diabetes they are used as a first-line treatment. Type 2 patients demanding insulin will likely have already tried these alternate therapies without success, or they may use these drugs in conjunction with insulin.

${ }^{9}$ There are nine health plan types: 1 - basic major medical, 2 - comprehensive (COMP), 3 - exclusive provider organization (EPO), 4 - health maintenance organization (HMO), 5 - non-capitated point of service (Non-cap POS), 6 - preferred provider organization (PPO), 7 - capitated or partially-capitated point-of-service (Cap or Part-Cap POS), 8 - consumer driven health plan (CDHP), and 9 - high deductible health plan (HDHP).
} 


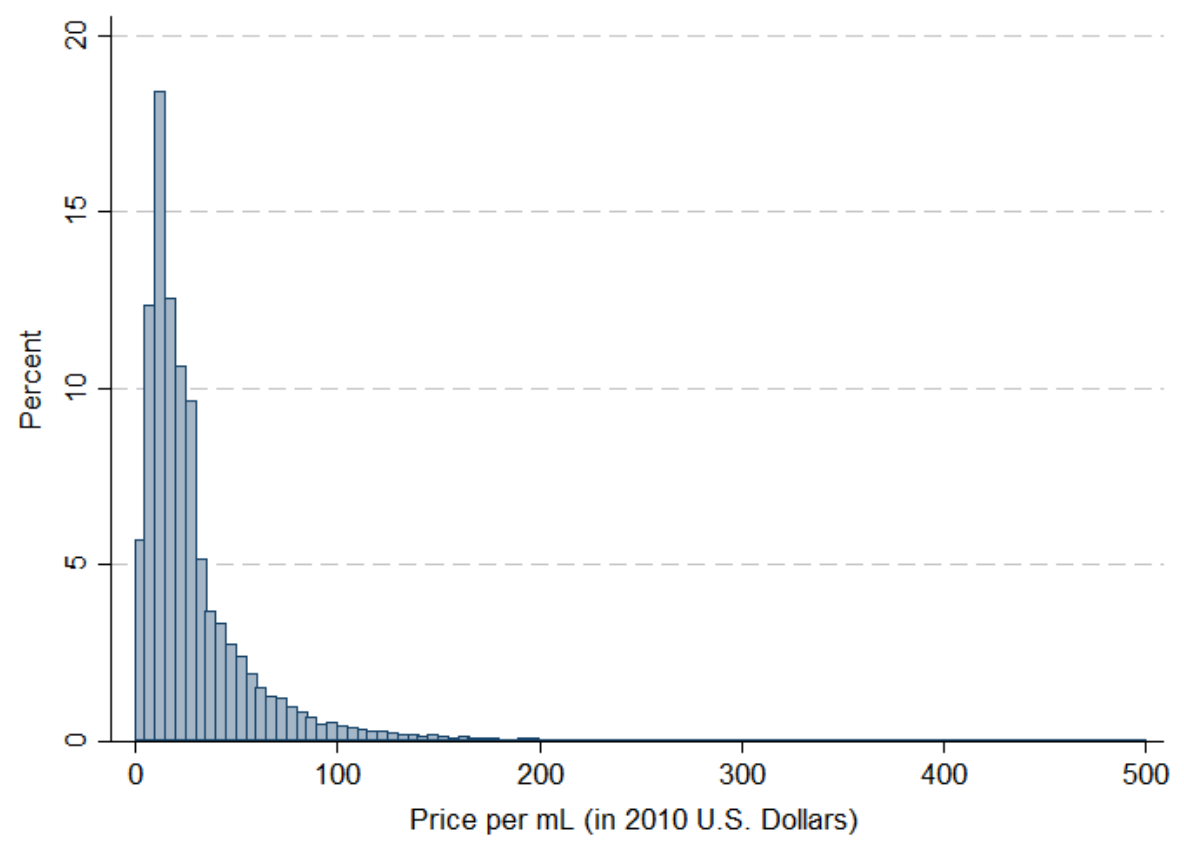

Figure 3: Distribution of Insulin Price

The next most common plan providers are HMO plans, 16.42 percent, and comprehensive plans, 12.36 percent. Figure 5 depicts the frequency of claims for insulin by brand. The most commonly used insulin brand is Lantus, 39.73 percent of all claims. Novolog and Humalog are the next most commonly used insulin brands, 20.30 and 17.85 percent, respectively.

The claims data was supplemented with additional data on drug characteristics obtained from Redbook and the Food and Drug Administration (FDA) Orangebook and Drugs@FDA database as well as information about drugs in the development pipeline from the United States Clinical Trials Online Registry. Drug attributes are matched to claims using the national drug code (NDC). Each national drug code identifies the size in mililiters $(\mathrm{mL})$, a description of the packaging, the strength in units per $\mathrm{mL}(\mathrm{U} / \mathrm{mL})$, the mechanism of action (peak, onset, and duration of the drug), and the insulin form (animal, human or analogue). We also obtain information on patents for each drug, and the patent expiration date to identify loss of exclusivity. ${ }^{10}$ Finally, pipeline shock indicators described previously are constructed using information from the United States Clinical Trials Online Registry and from the Drugs@FDA database. This information is consolidated for this analysis and listed in Table 8 in the Appendix.

Table 1 presents summary statistics for variables used in the analysis which are partitioned by market

\footnotetext{
${ }^{10}$ Of all insulin products under patent, those with patent expirations prior to 2017 are discontinued. The earliest loss of exclusivity of drugs considered here is June 20, 2017.
} 


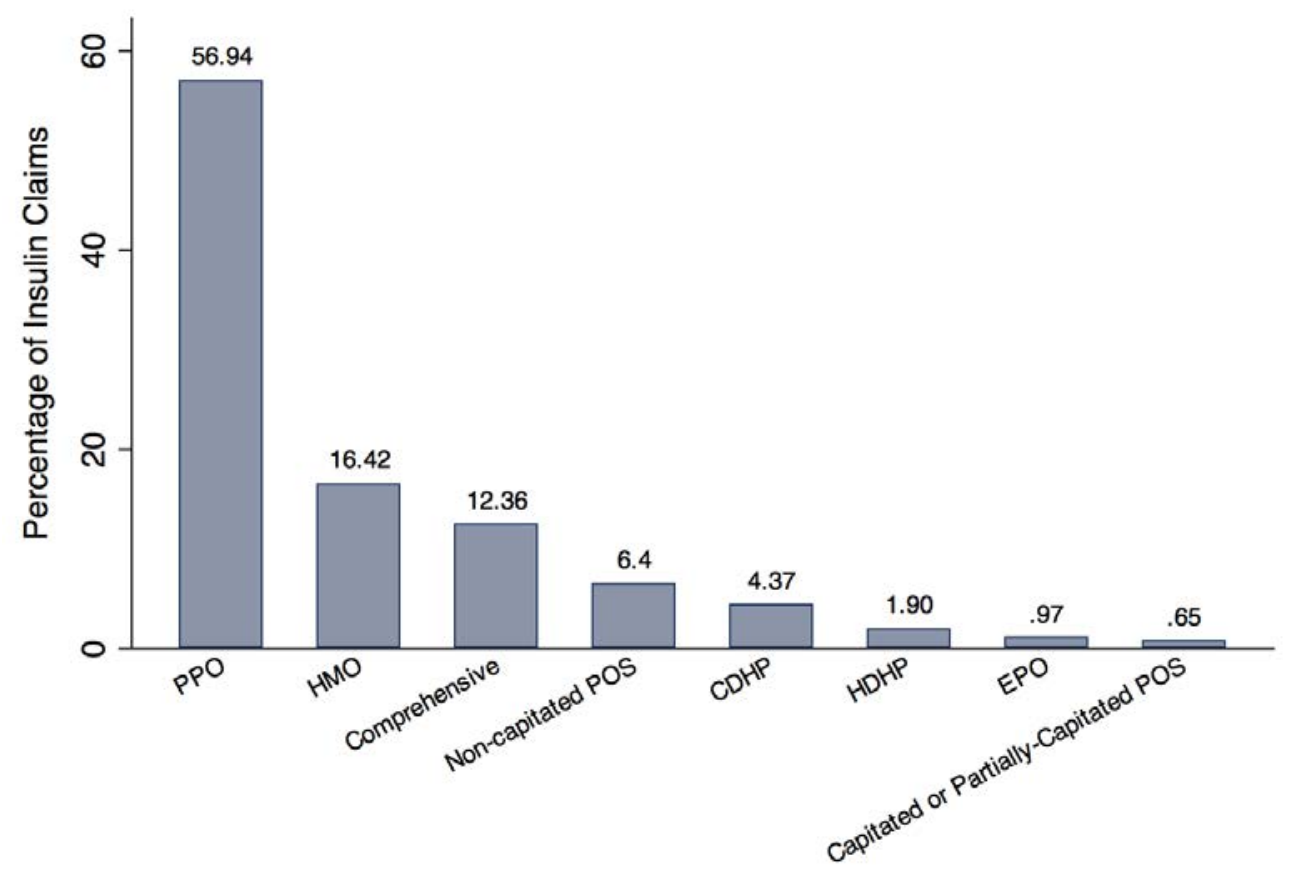

Figure 4: Percentage of Insulin Claims by Health Plan Type

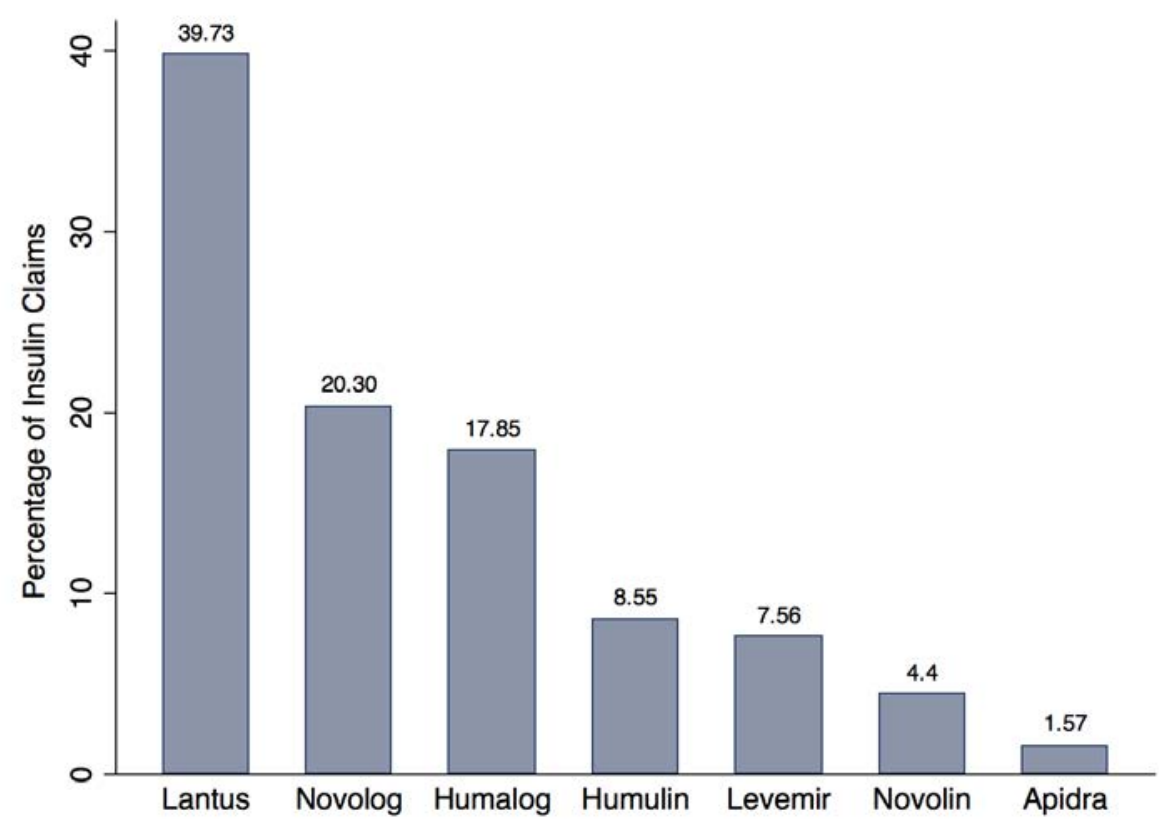

Figure 5: Percentage of Insulin Claims by Brand 
Table 1: Summary Statistics

Incumbent Insulins, 2007q1 to 2015q4

\begin{tabular}{lccccc}
\hline \hline Variable & Mean & Median & Std. Dev. & Min & Max \\
\hline Price & 30.46 & 20.42 & 33.63 & 0 & $3,074.73$ \\
Patient Price & 3.04 & 2.34 & 3.62 & 0 & 784.93 \\
Baseline Time on Market (in quarters) & 35.50 & 27 & 22.61 & 4 & 100 \\
Market Share, by NDC & 0.12 & 0.09 & 0.09 & 0 & 0.32 \\
Market Share, by Brand & 0.25 & 0.20 & 0.13 & 0 & 0.41 \\
\hline
\end{tabular}

Note. Summary statistics presented above, Incumbent Insulins, are calculated using observations included in the analysis.

Entrant Insulins, 2015q1 to 2015q4

\begin{tabular}{lccccc}
\hline \hline Variable & Mean & Median & Std. Dev. & Min & Max \\
\hline Price & 138.25 & 83.58 & 134.71 & 0 & $3,251.93$ \\
Patient Price & 13.73 & 9.73 & 24.30 & 0 & $1,220.07$ \\
Baseline Time on Market (in quarters) & -31.86 & -32 & 0.73 & -34 & -29 \\
Market Share, by NDC & 0.02 & 0.03 & 0.01 & 0 & 0.03 \\
Market Share, by Brand & 0.02 & 0.03 & 0.01 & 0 & 0.03 \\
\hline
\end{tabular}

Note. Summary statistics presented above, Entrant Insulins, are calculated using post-entry observations. They are for reference purposes only and are not included in the analysis which follows.

participation status. Incumbent drugs are insulins with approvals prior to the start of the panel. Entrant drugs are insulins in stages of the drug development pipeline during the panel. The analysis which follows considers only the prices of incumbent insulins, so the presentation of summary statistics for entrant insulins is only for informational purposes. There are several intuitive and revealing insights from this segmentation. First, median prices tend to be lower than average prices for both incumbent insulins and entrant insulins. The average time on the market for incumbent insulins at baseline (2007q1) is 35.5 quarters, over 8 years, and baseline time of the market for entrants is negative, by definition. Both prices and patient prices tend to be higher for entering drugs compared to incumbent drugs, indicating that new products may be vertically differentiated from existing products and therefore prices exhibit a markup. Market share tends to be higher for incumbent drugs compared to entrants, whether it is calculated by National Drug Code or by brand. In fact, the degree of market share loss immediately following entry in this market is quite low. 
Table 2: The Effect of Phase 3 Pipeline News Shocks on Incumbent Insulin Prices

\begin{tabular}{|c|c|c|c|}
\hline Variable & $\begin{array}{c}(1) \\
\text { Full Sample }\end{array}$ & $\begin{array}{c}(2) \\
\text { Analogue Only }\end{array}$ & $\begin{array}{c}(3) \\
\text { Human Only }\end{array}$ \\
\hline \multicolumn{4}{|l|}{ Phase 3 Shocks } \\
\hline $1^{\text {st }}$ Pipeline Shock $t$ & $\begin{array}{l}-0.726 \\
(0.795)\end{array}$ & $\begin{array}{l}-0.678 \\
(0.917)\end{array}$ & $\begin{array}{l}-1.215 \\
(0.790)\end{array}$ \\
\hline $2^{\text {nd }}$ Pipeline Shock $_{t}$ & $\begin{array}{l}-1.147 \\
(0.912)\end{array}$ & $\begin{array}{l}-1.247 \\
(1.076)\end{array}$ & $\begin{array}{l}-0.312 \\
(1.116)\end{array}$ \\
\hline $3^{\text {rd }}$ Pipeline Shock $_{t}$ & $\begin{array}{c}2.285^{* *} \\
(1.053)\end{array}$ & $\begin{array}{l}2.350^{* *} \\
(1.103)\end{array}$ & $\begin{array}{c}0.654 \\
(2.054)\end{array}$ \\
\hline $4^{t h}$ Pipeline Shock $_{t}$ & $\begin{array}{c}2.263^{* *} \\
(1.142)\end{array}$ & $\begin{array}{l}2.284^{*} \\
(1.178)\end{array}$ & $\begin{array}{l}1.117 \\
(2.177)\end{array}$ \\
\hline Time & $\begin{array}{c}0.715^{* * *} \\
(0.0957)\end{array}$ & $\begin{array}{c}0.810^{* * *} \\
(0.110)\end{array}$ & $\begin{array}{c}0.447^{* * *} \\
(0.0838)\end{array}$ \\
\hline Time $^{2}$ & $\begin{array}{c}0.0323^{* * *} \\
(0.00636)\end{array}$ & $\begin{array}{c}0.0311^{* * *} \\
(0.00709)\end{array}$ & $\begin{array}{r}0.0252^{* * *} \\
(0.00763)\end{array}$ \\
\hline Quarter 2 & $\begin{array}{l}-0.643 \\
(0.455)\end{array}$ & $\begin{array}{l}-0.678 \\
(0.517)\end{array}$ & $\begin{array}{l}-0.443 \\
(0.534)\end{array}$ \\
\hline Quarter 3 & $\begin{array}{l}-0.278 \\
(0.492)\end{array}$ & $\begin{array}{l}-0.312 \\
(0.555)\end{array}$ & $\begin{array}{l}-0.162 \\
(0.570)\end{array}$ \\
\hline Quarter 4 & $\begin{array}{l}-0.412 \\
(0.516)\end{array}$ & $\begin{array}{l}-0.411 \\
(0.581)\end{array}$ & $\begin{array}{l}-0.371 \\
(0.629)\end{array}$ \\
\hline \multicolumn{4}{|l|}{ Health Plan Type } \\
\hline Exclusive Provider Organization & $\begin{array}{c}-3.436^{* * *} \\
(0.308)\end{array}$ & $\begin{array}{c}-3.535^{* * *} \\
(0.354)\end{array}$ & $\begin{array}{c}-3.093^{* * *} \\
(0.364)\end{array}$ \\
\hline Health Maintenance Organization & $\begin{array}{c}-6.775^{* * * *} \\
(0.307)\end{array}$ & $\begin{array}{c}-6.919^{* * *} \\
(0.342)\end{array}$ & $\begin{array}{c}-5.803^{* * *} \\
(0.559)\end{array}$ \\
\hline Non-capitated Point of Service (POS) & $\begin{array}{c}-3.508^{* * *} \\
(0.301)\end{array}$ & $\begin{array}{c}-3.648^{* * * *} \\
(0.348)\end{array}$ & $\begin{array}{c}-2.776^{* * * *} \\
(0.285)\end{array}$ \\
\hline Preferred Provider Organization & $\begin{array}{c}-4.923^{* * *} \\
(0.238)\end{array}$ & $\begin{array}{c}-5.162^{* * *} \\
(0.276)\end{array}$ & $\begin{array}{c}-3.611^{* * *} \\
(0.274)\end{array}$ \\
\hline Capitated or Partially-capitated POS & $\begin{array}{c}-9.680^{* * *} \\
(0.553)\end{array}$ & $\begin{array}{c}-9.991^{* * *} \\
(0.619)\end{array}$ & $\begin{array}{c}-7.466^{* * *} \\
(0.587)\end{array}$ \\
\hline Consumer Driven Health Plan & $\begin{array}{c}-7.624^{* * *} \\
(0.306)\end{array}$ & $\begin{array}{c}-7.955^{* * *} \\
(0.345)\end{array}$ & $\begin{array}{c}-5.700^{* * *} \\
(0.375)\end{array}$ \\
\hline High Deductible Health Plan & $\begin{array}{c}-7.007^{* * *} \\
(0.319)\end{array}$ & $\begin{array}{c}-7.310^{* * * *} \\
(0.355)\end{array}$ & $\begin{array}{c}-5.814^{* * * *} \\
(0.394)\end{array}$ \\
\hline Constant & $\begin{array}{c}22.80^{* * *} \\
(0.758)\end{array}$ & $\begin{array}{c}23.76^{* * *} \\
(0.860)\end{array}$ & $\begin{array}{c}14.93^{* * *} \\
(0.784)\end{array}$ \\
\hline R-squared & 0.222 & 0.195 & 0.341 \\
\hline F-statistic & $410.81^{* * *}$ & $393.06^{* * *}$ & $144.42^{* * *}$ \\
\hline Observations & $27,359,428$ & $23,785,610$ & $3,573,818$ \\
\hline Number of drugs & 122 & 54 & 68 \\
\hline
\end{tabular}




\section{Results}

\subsection{The Effect of Pipeline Pressure on Incumbent Insulin Prices}

Initial results are displayed in Table 2. All results were obtained using drug-level fixed effects linear regressions. The first column presents results obtained using the full sample, while the second and third columns stratify by insulin type, analogue or human. There are less than 30 total claims for animal insulins, making it impossible to assess effects on the pricing of insulins of this type. The direction of pipeline shock effects are similar regardless of the sample considered, though there are minor differences in magnitude and significance. Response to competitive pressure in the pipeline is stronger for insulin analogues than for human versions of insulin. The first two shocks do not have a significant effect on price. However, the third and fourth shocks significantly increase insulin price, specifically among analogues. The biggest price effect is concentrated among insulin analogues. Prices are about $\$ 2.35$ larger per $\mathrm{mL}$ in quarters following the third pipeline shock compared to quarters prior to this shock. The fourth pipeline shock has an additionally positive effect on price, increasing insulin price per $\mathrm{mL}$ by about $\$ 2.28$ in quarters following this shock. For the average patient in this sample taking $12.48 \mathrm{ml}$ per month, this is an increase in the total amount paid for insulin of $\$ 29.33$ due to the third shock and an additional $\$ 28.45$ due to the final shock.

In general, price is increasing at an increasing rate over time, by about $\$ 1.34$ per quarter at the mean number of quarters since the first pipeline shock. ${ }^{11}$ Pipeline shocks reflect a shift in this more general time trend. Since identification of the pipeline shocks relies on a correct specification of the time trend, we also consider whether there is a systematic issue in the specification of the time trend by graphing the average residuals over time, provided in Figure 7 in the Appendix. Results also indicate that there is no cyclical dimension to pricing, that is, prices in later quarters are not significantly different than prices in the first quarter of the year. Lastly, the health plan type has a considerable impact on price. All health plan types covering insulin have lower prices than comprehensive health plans, with capitated or partially-capitated POS plans, consumer driven health plans, high deductible health plans, and health maintenance organization health plans having the biggest differences in price. This may be due to in part to plan structure, but could also be due to levels of insurer bargaining power associated with each plan type. Growing literature on insurer bargaining power and bargaining power in healthcare may contribute to our understanding of these results [Ho and Lee (2017); Gaynor, Ho and Town (2015); Ho (2009); and Capps, Dranove and Satterthwaite (2003)].

\footnotetext{
${ }^{11} \theta_{1}+2 \theta_{2}(E(t))=0.715+2(0.0323)(9.74)=1.344$
} 
Table 3: The Effect of Phase 3 Pipeline News Shocks on Patient Out-of-Pocket Prices

\begin{tabular}{|c|c|c|c|}
\hline Variable & $\begin{array}{c}(1) \\
\text { Full Sample }\end{array}$ & $\begin{array}{c}(2) \\
\text { Analogue Only }\end{array}$ & $\begin{array}{c}\text { (3) } \\
\text { Human Only }\end{array}$ \\
\hline \multicolumn{4}{|l|}{ Phase 3 Shocks } \\
\hline $1^{\text {st }}$ Pipeline Shock $_{t}$ & $\begin{array}{c}-0.263^{* * *} \\
(0.0571)\end{array}$ & $\begin{array}{c}-0.274^{* * *} \\
(0.0643)\end{array}$ & $\begin{array}{c}-0.205^{* * *} \\
(0.0739)\end{array}$ \\
\hline $2^{\text {nd }}$ Pipeline Shock $_{t}$ & $\begin{array}{c}0.142^{* * *} \\
(0.0397)\end{array}$ & $\begin{array}{c}0.144^{* * *} \\
(0.0444)\end{array}$ & $\begin{array}{c}0.124^{*} \\
(0.0750)\end{array}$ \\
\hline $3^{r d}$ Pipeline Shock ${ }_{t}$ & $\begin{array}{c}0.161^{* * *} \\
(0.0595)\end{array}$ & $\begin{array}{c}0.166^{* * *} \\
(0.0611)\end{array}$ & $\begin{array}{l}0.0728 \\
(0.175)\end{array}$ \\
\hline $4^{t h}$ Pipeline Shock $t$ & $\begin{array}{c}0.384^{* * *} \\
(0.0604)\end{array}$ & $\begin{array}{c}0.373^{* * *} \\
(0.0623)\end{array}$ & $\begin{array}{c}0.472^{* * *} \\
(0.162)\end{array}$ \\
\hline Time & $\begin{array}{l}0.101^{* * *} \\
(0.00541)\end{array}$ & $\begin{array}{l}0.103^{* * *} \\
(0.00629)\end{array}$ & $\begin{array}{c}0.0907^{* * *} \\
(0.00771)\end{array}$ \\
\hline Time $^{2}$ & $\begin{array}{c}-0.00203^{* * *} \\
(0.000309)\end{array}$ & $\begin{array}{c}-0.00208^{* * *} \\
(0.000348)\end{array}$ & $\begin{array}{c}-0.00204^{* * *} \\
(0.000433)\end{array}$ \\
\hline Quarter 2 & $\begin{array}{c}-0.0705^{* *} \\
(0.0276)\end{array}$ & $\begin{array}{c}-0.0704^{* *} \\
(0.0302)\end{array}$ & $\begin{array}{l}-0.0708 \\
(0.0490)\end{array}$ \\
\hline Quarter 3 & $\begin{array}{c}-0.172^{* * *} \\
(0.0264)\end{array}$ & $\begin{array}{c}-0.178^{* * *} \\
(0.0288)\end{array}$ & $\begin{array}{c}-0.136^{* * *} \\
(0.0477)\end{array}$ \\
\hline Quarter 4 & $\begin{array}{c}-0.357^{* * *} \\
(0.0289)\end{array}$ & $\begin{array}{c}-0.369^{* * *} \\
(0.0316)\end{array}$ & $\begin{array}{c}-0.273^{* * *} \\
(0.0483)\end{array}$ \\
\hline \multicolumn{4}{|l|}{ Health Plan Type } \\
\hline Exclusive Provider Organization & $\begin{array}{c}-0.636^{* * *} \\
(0.0519)\end{array}$ & $\begin{array}{c}-0.595^{* * *} \\
(0.0580)\end{array}$ & $\begin{array}{c}-0.807^{* * * *} \\
(0.0661)\end{array}$ \\
\hline Health Maintenance Organization & $\begin{array}{c}-0.349 * * * \\
(0.0425)\end{array}$ & $\begin{array}{c}-0.264^{* * * *} \\
(0.0480)\end{array}$ & $\begin{array}{c}-0.745^{* * * *} \\
(0.0833)\end{array}$ \\
\hline Non-capitated Point of Service (POS) & $\begin{array}{l}-0.0206 \\
(0.0343)\end{array}$ & $\begin{array}{c}-0.00263 \\
(0.0402)\end{array}$ & $\begin{array}{l}-0.0210 \\
(0.0487)\end{array}$ \\
\hline Preferred Provider Organization & $\begin{array}{c}0.0387 \\
(0.0431)\end{array}$ & $\begin{array}{c}0.0811 \\
(0.0507)\end{array}$ & $\begin{array}{c}-0.159^{* * *} \\
(0.0479)\end{array}$ \\
\hline Capitated or Partially-capitated POS & $\begin{array}{c}-0.597^{* * *} \\
(0.0520)\end{array}$ & $\begin{array}{c}-0.604^{* * *} \\
(0.0585)\end{array}$ & $\begin{array}{c}-0.336^{* * *} \\
(0.0837)\end{array}$ \\
\hline Consumer Driven Health Plan & $\begin{array}{c}-0.773^{* * *} \\
(0.0721)\end{array}$ & $\begin{array}{c}-0.701^{* * * *} \\
(0.0814)\end{array}$ & $\begin{array}{c}-1.277^{* * * *} \\
(0.0734)\end{array}$ \\
\hline High Deductible Health Plan & $\begin{array}{c}-0.981^{* * *} \\
(0.0813)\end{array}$ & $\begin{array}{c}-0.903^{* * *} \\
(0.0906)\end{array}$ & $\begin{array}{c}-1.624^{* * *} \\
(0.0813)\end{array}$ \\
\hline Constant & $\begin{array}{c}2.731^{* * *} \\
(0.0577)\end{array}$ & $\begin{array}{c}2.719^{* * *} \\
(0.0652)\end{array}$ & $\begin{array}{c}2.682^{* * *} \\
(0.0814)\end{array}$ \\
\hline R-squared & 0.062 & 0.055 & 0.101 \\
\hline F-statistic & $295.21^{* * *}$ & $295.38^{* * *}$ & $191.65^{* * *}$ \\
\hline Number of drugs & 122 & 54 & 68 \\
\hline Observations & $27,359,428$ & $23,785,610$ & $3,573,818$ \\
\hline
\end{tabular}

Note. All estimates are obtained using OLS with drug-level fixed effects. The dependent variable in all specifications is patient price per $\mathrm{mL}$ which includes all patient out-of-pocket costs, adjusted for inflation. Standard errors are clustered at the drug-quarter level. All health plan coefficients should be interpreted as the change in patient out-of-pocket costs relative to the base health plan, comprehensive.

* Statistically significant at the 10 percent level

** Statistically significant at the 5 percent level

*** Statistically significant at the 1 percent level 
Table 3 provides estimates of the effect of pipeline news shocks on patient out-of-pocket costs. Pipeline shocks have largely significant effects on patient prices, as price changes are passed on to consumers. All but one of these pipeline shocks, the first, has a positive effect on price. The second, third, and fourth pipeline shocks are associated with price increases of $\$ 0.14, \$ 0.16$, and $\$ 0.38$, respectively, in quarters after the shocks. All of these price effects are statistically significant at the one percent level, but significant responses are mostly concentrated among insulin analogues. For the average patient in this sample taking $12.48 \mathrm{ml}$ per month, this is an increase in out-of-pocket costs for insulin of $\$ 1.74, \$ 2.00$, and $\$ 4.74$, respectively, or a total of $\$ 26.48$ additional out-of-pocket costs over 8 years due to competition pressure from the pipeline. On average, that's an additional $\$ 3.31$ per year.

The first pipeline shock decreases patient price following the shock by about $\$ 0.26$. This result is also statistically significant at the one percent level. This suggests that there may be something different about the first pipeline shock. This market information shock represents Afrezza completing the last phase of drug development has a significantly negative effect on price, but the rest of the pipeline shocks increase price. This is likely due to the degree of product differentiation associated with Afrezza. Afrezza is an inhale-able insulin, while the rest of the drugs on the market are injectables. This pipeline shock decreases out-of-pocket costs by about $\$ 3.24$ for the average patient in this sample, bringing the total change in patient costs due to pipeline pressure to an increase of about $\$ 23.24$ over 8 years. This also demonstrates that incumbent manufacturers may have a holistic view of the probability of entry as indicated by information from the pipeline. As more than one potential competitor completes phase 3 , the probability that one of them will eventually be successful increases. As demonstrated in the theory, manufacturers will increase price when facing relatively inelastic demand in a setting where entry is becoming more likely.

Trends in patient prices are somewhat different than trends for total prices. Patient out-of-pocket costs are lower for only a few plan types relative to comprehensive plans. This includes EPOs, HMOs, Capitated or Partially-capitated POS, CDHPs, and HDHPs. High deductible plans are associated with the biggest reduction in patient prices relative to comprehensive plans, which may demonstrate that patients in highdeductible plans are much more price sensitive than patients in other health plans. In addition, note that quarter of the year effects have considerably significant effect on patient out-of-pocket costs. Patient prices are significantly lower in the second, third, and fourth quarters relative to the first quarter of the year, and patient out-of-pocket costs are lowest in the fourth quarter relative to the first quarter. This likely reflects the decline in out-of-pocket costs as patients hit their deductible during the year. 


\subsubsection{Verifying Shock Exogeneity: Restricting the Analysis to External Firm Shocks}

Incumbent insulins in our sample are only manufactured by three drug companies, Sanofi, Novo Nordisk, and Eli Lilly. Each of these firms also has another insulin in development during our panel that clears various phases of the drug development pipeline. In this market, an incumbent firm with a product in one category of insulin may be in drug development for a different insulin in another category. We will consider the issue of category and the definition of the market in detail in a later section. For now, let us only consider the effect this may have on the exogeneity of the pipeline shocks. For a firm with both an incumbent drug and a new drug in the development pipeline, the information about success in the pipeline will not necessarily be a "shock" to this incumbent at all. Firms may internalize their success in the drug development pipeline as they anticipate pricing effects from their new drug. Therefore, we also conduct firm-specific pipeline shock tests. While it is reasonable to assume that external pipeline shocks, across firms, are exogenous, it is may be inappropriate to assume that internal pipeline shocks, within firm, are exogenous. Therefore, we stratify our sample at the firm-level, and consider only the shocks that are external to the firm. In other words, we drop pipeline shocks from a firm's own drug.

Table 4 presents results from firm-specific shock tests. Note that qualitatively, the impact of each shock is qualitatively similar both in the full sample without regard to strict shock exogeneity and by firm, excluding shocks which may be internalized. However, it is striking to note that Eli Lilly and Sanofi prices changes, drive the results in the full sample. Eli Lilly increases prices by about $\$ 4.19$ in quarters following the fourth shock, and Sanofi increases prices by about $\$ 4.47$ in quarters following the third shock. These effects are only somewhat significant, at the ten and five percent levels, respectively. There is no significant change in prices among Novo Nordisks insulin products in response to any of the pipeline shocks. It is worth considering how each of these firms may view these pipeline shocks. The amount of competitive pressure associated with pipeline shocks will likely depend on the degree to which these products are used as perfect and/or imperfect substitutes in practice and whether or not they can also be used in complementary ways. Section 5.2 details particular categories of these drugs to highlight the nature of competition in these markets.

\subsubsection{Differential Effects by Plan Design - Copayment or Coinsurance}

As discussed in the theoretical model presented previously, patients facing copayment for prescription drugs tend to be less price sensitive than those facing coinsurance. In the insulin market considered here, 74.9 percent of claims for insulin require a copayment only. 16.7 percent of claims have no patient out-of- 
Table 4: Verifying Shock Exogeneity: Firm-specific Shock Tests

\begin{tabular}{|c|c|c|c|c|}
\hline Variable & $\begin{array}{l}(1) \\
\text { Full Sample }\end{array}$ & $\begin{array}{c}(2) \\
\text { Eli Lilly }\end{array}$ & $\begin{array}{c}(3) \\
\text { Sanofi }\end{array}$ & $\begin{array}{c}(4) \\
\text { Novo Nordisk }\end{array}$ \\
\hline \multicolumn{5}{|l|}{ Phase 3 Shocks } \\
\hline $1^{\text {st }}$ Pipeline Shock $_{t}$ & $\begin{array}{l}-0.726 \\
(0.795)\end{array}$ & $\begin{array}{l}-0.109 \\
(1.437)\end{array}$ & $\begin{array}{l}-1.567 \\
(0.950)\end{array}$ & $\begin{array}{c}0.609 \\
(1.538)\end{array}$ \\
\hline $2^{\text {nd }}$ Pipeline Shock $t$ & $\begin{array}{l}-1.147 \\
(0.912)\end{array}$ & $\begin{array}{l}-1.726 \\
(1.065)\end{array}$ & $\begin{array}{l}-1.112 \\
(1.681)\end{array}$ & \\
\hline $3^{\text {rd }}$ Pipeline Shock $_{t}$ & $\begin{array}{l}2.285^{* *} \\
(1.053)\end{array}$ & & $\begin{array}{l}4.467^{* *} \\
(1.723)\end{array}$ & $\begin{array}{l}1.936 \\
(1.460)\end{array}$ \\
\hline $4^{\text {th }}$ Pipeline Shock $t$ & $\begin{array}{c}2.263^{* *} \\
(1.142)\end{array}$ & $\begin{array}{l}4.192^{*} \\
(2.167)\end{array}$ & & $\begin{array}{c}1.522 \\
(1.638)\end{array}$ \\
\hline Time & $\begin{array}{c}0.715^{* * *} \\
(0.0957)\end{array}$ & $\begin{array}{c}0.668^{* * *} \\
(0.164)\end{array}$ & $\begin{array}{c}0.833^{* * *} \\
(0.141)\end{array}$ & $\begin{array}{c}0.466^{* * *} \\
(0.164)\end{array}$ \\
\hline Time $^{2}$ & $\begin{array}{c}0.0323^{* * *} \\
(0.00636)\end{array}$ & $\begin{array}{c}0.0435^{* * * *} \\
(0.00901)\end{array}$ & $\begin{array}{c}0.0267^{* * * *} \\
(0.00801)\end{array}$ & $\begin{array}{c}0.0376^{* * *} \\
(0.00927)\end{array}$ \\
\hline Quarter 2 & $\begin{array}{l}-0.643 \\
(0.455)\end{array}$ & $\begin{array}{l}-0.824 \\
(0.777)\end{array}$ & $\begin{array}{l}-0.408 \\
(0.740)\end{array}$ & $\begin{array}{l}-0.458 \\
(0.714)\end{array}$ \\
\hline Quarter 3 & $\begin{array}{l}-0.278 \\
(0.492)\end{array}$ & $\begin{array}{r}-0.0705 \\
(0.839)\end{array}$ & $\begin{array}{l}-0.283 \\
(0.810)\end{array}$ & $\begin{array}{l}-0.178 \\
(0.749)\end{array}$ \\
\hline Quarter 4 & $\begin{array}{l}-0.412 \\
(0.516)\end{array}$ & $\begin{array}{l}-0.120 \\
(0.855)\end{array}$ & $\begin{array}{l}-0.687 \\
(0.868)\end{array}$ & $\begin{array}{l}-0.181 \\
(0.782)\end{array}$ \\
\hline \multicolumn{5}{|l|}{ Health Plan Type } \\
\hline Exclusive Provider Organization & $\begin{array}{c}-3.436^{* * *} \\
(0.308)\end{array}$ & $\begin{array}{c}-4.266^{* * *} \\
(0.513)\end{array}$ & $\begin{array}{c}-4.248^{* * *} \\
(0.394)\end{array}$ & $\begin{array}{c}-1.326^{*} \\
(0.698)\end{array}$ \\
\hline Health Maintenance Organization & $\begin{array}{c}-6.775^{* * *} \\
(0.307)\end{array}$ & $\begin{array}{c}-9.832^{* * *} \\
(0.575)\end{array}$ & $\begin{array}{c}-7.144^{* * *} \\
(0.487)\end{array}$ & $\begin{array}{c}-3.591^{* * *} \\
(0.542)\end{array}$ \\
\hline Non-capitated Point of Service (POS) & $\begin{array}{c}-3.508^{* * *} \\
(0.301)\end{array}$ & $\begin{array}{c}-3.589^{* * *} \\
(0.429)\end{array}$ & $\begin{array}{c}-4.506^{* * *} \\
(0.510)\end{array}$ & $\begin{array}{c}-1.678^{* * *} \\
(0.539)\end{array}$ \\
\hline Preferred Provider Organization & $\begin{array}{c}-4.923^{* * *} \\
(0.238)\end{array}$ & $\begin{array}{c}-5.972^{* * *} \\
(0.366)\end{array}$ & $\begin{array}{c}-5.878^{* * *} \\
(0.319)\end{array}$ & $\begin{array}{c}-2.387^{* * *} \\
(0.529)\end{array}$ \\
\hline Capitated or Partially-capitated POS & $\begin{array}{c}-9.680^{* * *} \\
(0.553)\end{array}$ & $\begin{array}{c}-10.36^{* * *} \\
(0.720)\end{array}$ & $\begin{array}{c}-10.73^{* * *} \\
(1.058)\end{array}$ & $\begin{array}{c}-7.267^{* * *} \\
(0.812)\end{array}$ \\
\hline Consumer Driven Health Plan & $\begin{array}{c}-7.624^{* * *} \\
(0.306)\end{array}$ & $\begin{array}{c}-8.043^{* * *} \\
(0.536)\end{array}$ & $\begin{array}{c}-8.479 * * * \\
(0.490)\end{array}$ & $\begin{array}{c}-5.903^{* * *} \\
(0.541)\end{array}$ \\
\hline High Deductible Health Plan & $\begin{array}{c}-7.007^{* * *} \\
(0.319)\end{array}$ & $\begin{array}{c}-7.472^{* * *} \\
(0.518)\end{array}$ & $\begin{array}{c}-8.466^{* * *} \\
(0.422)\end{array}$ & $\begin{array}{c}-4.347^{* * *} \\
(0.604)\end{array}$ \\
\hline Constant & $\begin{array}{c}22.80^{* * *} \\
(0.758)\end{array}$ & $\begin{array}{c}25.69^{* * *} \\
(1.307)\end{array}$ & $\begin{array}{c}21.38^{* * *} \\
(1.068)\end{array}$ & $\begin{array}{c}21.04^{* * *} \\
(1.353)\end{array}$ \\
\hline R-squared & 0.222 & 0.274 & 0.178 & 0.212 \\
\hline F-statistic & $410.81^{* * *}$ & $201.25^{* * *}$ & $254.20^{* * *}$ & $209.75^{* * *}$ \\
\hline Observations & $27,359,428$ & $7,215,129$ & $11,299,605$ & $8,834,609$ \\
\hline Number of drugs & 122 & 40 & 7 & 31 \\
\hline
\end{tabular}


Table 5: Differential Effects: Copayment or Coinsurance

\begin{tabular}{|c|c|c|c|c|}
\hline Variable & $\begin{array}{c}\text { (1) } \\
\text { Price }\end{array}$ & $\begin{array}{c}(2) \\
\text { Patient } \\
\text { Out-of-Pocket }\end{array}$ & Price & $\begin{array}{c}(4) \\
\text { Patient } \\
\text { Out-of-Pocket }\end{array}$ \\
\hline & \multicolumn{2}{|c|}{ Copayment Only } & \multicolumn{2}{|c|}{ Coinsurance Only } \\
\hline Phase 3 Shocks & & & & \\
\hline $1^{s t}$ Pipeline Shock $_{t}$ & $\begin{array}{l}-0.640 \\
(0.807)\end{array}$ & $\begin{array}{c}-0.226^{* * *} \\
(0.0488)\end{array}$ & $\begin{array}{l}-0.342 \\
(1.004)\end{array}$ & $\begin{array}{c}-0.513^{* * *} \\
(0.165)\end{array}$ \\
\hline $2^{\text {nd }}$ Pipeline Shock $_{t}$ & $\begin{array}{l}-1.223 \\
(0.952)\end{array}$ & $\begin{array}{c}-0.0810^{*} \\
(0.0421)\end{array}$ & $\begin{array}{c}-1.934^{* *} \\
(0.917)\end{array}$ & $\begin{array}{c}0.202^{* *} \\
(0.100)\end{array}$ \\
\hline $3^{r d}$ Pipeline Shock $_{t}$ & $\begin{array}{l}2.103^{*} \\
(1.154)\end{array}$ & $\begin{array}{c}0.0906 \\
(0.0641)\end{array}$ & $\begin{array}{c}4.374^{* * *} \\
(0.811)\end{array}$ & $\begin{array}{l}0.0570 \\
(0.103)\end{array}$ \\
\hline $4^{t h}$ Pipeline Shock $_{t}$ & $\begin{array}{l}2.376^{*} \\
(1.281)\end{array}$ & $\begin{array}{c}0.381^{* * *} \\
(0.0708)\end{array}$ & $\begin{array}{c}3.831^{* * *} \\
(0.866)\end{array}$ & $\begin{array}{c}0.457^{* * *} \\
(0.115)\end{array}$ \\
\hline Time & $\begin{array}{c}0.797^{* * *} \\
(0.0970)\end{array}$ & $\begin{array}{l}0.108^{* * *} \\
(0.00485)\end{array}$ & $\begin{array}{c}0.561^{* * *} \\
(0.109)\end{array}$ & $\begin{array}{c}0.227^{* * *} \\
(0.0152)\end{array}$ \\
\hline Time $^{2}$ & $\begin{array}{c}0.0300 * * * \\
(0.00651)\end{array}$ & $\begin{array}{c}-0.00137^{* * *} \\
(0.000312)\end{array}$ & $\begin{array}{c}0.0148^{* * *} \\
(0.00517)\end{array}$ & $\begin{array}{c}-0.00202^{* * *} \\
(0.000683)\end{array}$ \\
\hline Quarter 2 & $\begin{array}{c}-0.896^{*} \\
(0.476)\end{array}$ & $\begin{array}{c}-0.0610^{* *} \\
(0.0264)\end{array}$ & $\begin{array}{l}-0.404 \\
(0.551)\end{array}$ & $\begin{array}{c}-0.0170 \\
(0.0761)\end{array}$ \\
\hline Quarter 3 & $\begin{array}{l}-0.504 \\
(0.505)\end{array}$ & $\begin{array}{c}-0.0612^{* *} \\
(0.0271)\end{array}$ & $\begin{array}{l}-0.410 \\
(0.543)\end{array}$ & $\begin{array}{c}0.0847 \\
(0.0685)\end{array}$ \\
\hline Quarter 4 & $\begin{array}{l}-0.651 \\
(0.534)\end{array}$ & $\begin{array}{c}-0.156^{* * *} \\
(0.0279)\end{array}$ & $\begin{array}{l}-0.840 \\
(0.527)\end{array}$ & $\begin{array}{c}-0.144^{* *} \\
(0.0697)\end{array}$ \\
\hline Health Plan Type & & & & \\
\hline Exclusive Provider Organization & $\begin{array}{c}-4.329^{* * *} \\
(0.280)\end{array}$ & $\begin{array}{c}-1.255^{* * *} \\
(0.0579)\end{array}$ & $\begin{array}{c}-1.485^{*} \\
(0.774)\end{array}$ & $\begin{array}{c}1.574^{* * *} \\
(0.149)\end{array}$ \\
\hline Health Maintenance Organization & $\begin{array}{c}-7.620^{* * *} \\
(0.292)\end{array}$ & $\begin{array}{c}-0.748^{* * *} \\
(0.0399)\end{array}$ & $\begin{array}{c}-5.041^{* * *} \\
(0.644)\end{array}$ & $\begin{array}{c}2.719^{* * *} \\
(0.152)\end{array}$ \\
\hline Non-capitated Point of Service (POS) & $\begin{array}{c}-4.234^{* * *} \\
(0.264)\end{array}$ & $\begin{array}{c}-0.443^{* * *} \\
(0.0346)\end{array}$ & $\begin{array}{c}-5.532^{* * *} \\
(0.659)\end{array}$ & $\begin{array}{l}0.662^{* * *} \\
(0.0747)\end{array}$ \\
\hline Preferred Provider Organization & $\begin{array}{c}-4.678^{* * *} \\
(0.221)\end{array}$ & $\begin{array}{c}-0.194^{* * *} \\
(0.0278)\end{array}$ & $\begin{array}{c}-1.833^{* *} \\
(0.722)\end{array}$ & $\begin{array}{c}0.881^{* * *} \\
(0.0720)\end{array}$ \\
\hline Capitated or Partially-capitated POS & $\begin{array}{c}-10.04^{* * *} \\
(0.504)\end{array}$ & $\begin{array}{c}-0.912^{* * *} \\
(0.0575)\end{array}$ & $\begin{array}{c}-4.653^{* * *} \\
(0.801)\end{array}$ & $\begin{array}{c}0.321^{* *} \\
(0.149)\end{array}$ \\
\hline Consumer Driven Health Plan & $\begin{array}{c}-8.173^{* * *} \\
(0.288)\end{array}$ & $\begin{array}{c}0.522^{* * *} \\
(0.0632)\end{array}$ & $\begin{array}{c}-5.375^{* * *} \\
(0.767)\end{array}$ & $\begin{array}{c}0.741^{* * *} \\
(0.0838)\end{array}$ \\
\hline High Deductible Health Plan & $\begin{array}{c}-5.347^{* * *} \\
(0.341)\end{array}$ & $\begin{array}{l}-0.0595 \\
(0.0571)\end{array}$ & $\begin{array}{l}-0.745 \\
(0.798)\end{array}$ & $\begin{array}{c}0.561^{* * *} \\
(0.102)\end{array}$ \\
\hline Constant & $\begin{array}{c}23.62^{* * *} \\
(0.768)\end{array}$ & $\begin{array}{c}3.267^{* * *} \\
(0.0508)\end{array}$ & $\begin{array}{c}22.37^{* * *} \\
(1.019)\end{array}$ & $\begin{array}{c}2.345^{* * *} \\
(0.118)\end{array}$ \\
\hline R-squared & 0.234 & 0.093 & 0.177 & 0.167 \\
\hline F-statistic & $299.51^{* * *}$ & $368.12^{* * *}$ & $159.93^{* * *}$ & $335.91^{* * *}$ \\
\hline Observations & $20,520,743$ & $20,520,743$ & $2,317,705$ & $2,317,705$ \\
\hline Number of drugs & 117 & 117 & 97 & 97 \\
\hline
\end{tabular}


pocket costs, ${ }^{12}$ neither copay nor coinsurance. The remaining 8.4 percent of claims is comprised mostly of payments with coinsurance only (8.2 percent) and a combination of copayment and coinsurance $(0.2$ percent). Therefore, it is reasonable to expect less price sensitivity from consumers covered by a plan with tiered copays instead of coinsurance. In this case, it may be advantageous to manufacturers to offer lower prices to plans with coinsurance than those with copayments. We conduct another specification, allowing prices to differ according to the structure of patient out-of-pocket costs. This will effectively serve as a proxy to group patients by their price elasticity.

In general, the effect of pipeline shocks on both price and patient out-of-pocket costs is qualitatively similar for both claims requiring a copayment and claims requiring coinsurance. However, the size and significance of pipeline shock effects is larger and more significant for claims with coinsurance compared to claims with copayment. This result is surprising, given that we postulated that patients under coinsurance would be more price sensitive than those facing copayment. The positive effect on price from the third shock is approximately $\$ 2.27$ more among claims with coinsurance, and the positive effect on price from the fourth shock is about $\$ 1.45$ more among coinsurance claims. Manufacturers may offer bigger discounts and/or different rebates for certain plans with copayment since they comprise a larger part of the market. Unfortunately, drug-level rebates are proprietary and the size of discounts cannot be assessed with claims data. This could also reflect a larger degree of bargaining power for the manufacturer compared to the insurer among plans with coinsurance. Without additional data on these contractural arrangements, it is unclear what may be driving this difference.

\subsection{The Effect of Pipeline News on Insulin Prices by Category}

The preliminary market definition is quite wide, and assumes that all insulin drugs compete with one another. A narrow market definition would specify that insulin products only compete with one another within category. We classify drugs into three market categories - bolus, basal, and mixed. This terminology is derived from the medical terminology which indicates how an insulin is absorbed and metabolized by the body. These categories are defined by three factors, onset, peak, and duration, of the drug. Bolus insulins tend to have a quick onset, moderate peaks, and moderate durations. Basal insulins tend to have slow onset, longer peaks, and longer durations. Mixed insulins typically contain both a bolus and basal insulin, and have a quick onset, long peak, and long duration. These characteristics of incumbent and potential entrant drugs are presented in Table 6. A range is provided because each drug formulation is absorbed

\footnotetext{
${ }^{12}$ The majority of these claims are for older versions of insulin provided at low costs.
} 
Table 6: Narrow Market Definition

\begin{tabular}{|c|c|c|c|}
\hline Category & Onset & Peak & Duration \\
\hline Bolus & $\approx 0.5 \mathrm{hrs}$ or less & $0.5-3.5 \mathrm{hrs}$ & $2-8 \mathrm{hrs}$ \\
\hline Basal & $1-6 \mathrm{hrs}$ & $4-12$ hrs or No Peak & $7-24$ hrs or more \\
\hline Mix & $\approx 0.5 \mathrm{hrs}$ or less & $0.5-12 \mathrm{hrs}$ & $18-24$ hrs or more \\
\hline Category & Incumbent Drugs & & Entrant Drugs \\
\hline Bolus & \multicolumn{2}{|c|}{$\begin{array}{l}\text { Apidra, Humalog, Novolog, } \\
\text { Humulin R, Novolin R }\end{array}$} & Afrezza \\
\hline Basal & \multicolumn{2}{|c|}{$\begin{array}{l}\text { Lantus, Levemir, Humulin N, } \\
\text { Novolin } \mathbf{N}\end{array}$} & Basaglar, Toujeo, Tresiba \\
\hline Mix & \multicolumn{2}{|c|}{$\begin{array}{l}\text { Humalog } 50 / 50 \text { and } 75 / 25, \text { Novolog } 70 / 30, \\
\text { Humulin } 70 / 30, \text { Novolin } 70 / 30\end{array}$} & Ryzodeg 70/30 \\
\hline
\end{tabular}

Note. Drugs listed in bold text are incumbent insulins.

somewhat differently, both between drugs and by different patients. For example, Humalog and Apidra insulins have somewhat different peak, onsets, and durations, even though they are both used as "bolus" insulins. Similarly, one patient may experience a rapid-acting insulin peak at one hour while another patient experiences the peak at 1.5 hours using the same drug.

Within category, insulins can usually be substituted, with the caveat that counseling/education may be needed to help assure adequate glucose coverage and safety in the transition. Between categories, it's difficult to specify the degree of substitutability as it may depend on an individual patient's insulin sensitivity or resistance as well as an individual patient's treatment therapy. Therefore, it is possible that manufacturers only see potential competitors "within category" as a competitive threat. Insulins "between categories" are often used in complementary ways. For example, consider these two treatment options. A patient can use long-acting insulin to provide basal glucose control in conjunction with a rapid-acting insulin to provide bolus control. A patient can also use only rapid-acting insulin delivered in small increments throughout the day to provide both basal and bolus control. Both treatment options can achieve the treatment goal of glucose control. Figure 6 demonstrates that 61.81 percent of patients in the sample fill a prescription for both a basal and bolus insulin, suggesting the majority of patients use these between category drugs as complements. ${ }^{13}$

Phase 3 pipeline shocks were constructed similarly in this specification. Because only one bolus insulin and one mix insulin were in the clinical trials phase of the drug development pipeline over this time frame,

\footnotetext{
${ }^{13}$ See Table 10 in the Appendix for number of claims.
} 


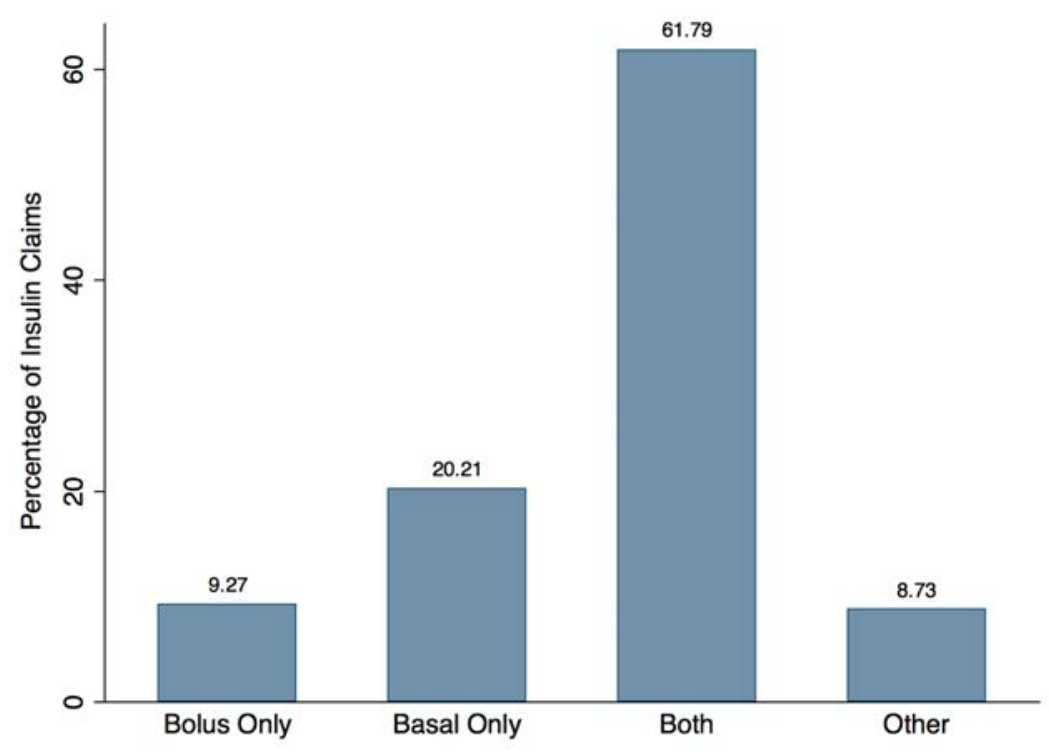

Figure 6: Insulin Treatment Combinations

there is only one pipeline shock in each of these categories. There were three phase 3 pipeline shocks in the basal category. Results from this specification are provided in Table 7. Note that the majority of the large and significant effects are isolated in the basal category. This matches the theory where we see that an increase in the probability of entry can drive escalating prices. Since the basal insulin category is the only category in which more than one potential entrant successfully clears phase 3 of drug development, it may be the only category where incumbent manufacturers have a large degree of confidence that probability of entry is likely. This specification also reveals that the specifics of the shock may matter substantially. The driving shock in the basal category is the Basaglar shock.

\subsection{Other Robustness Checks}

We test whether our results are robust to several other confounders that may affect the pricing decision. Regardless of how these factors affect the pricing decision, it is unlikely that these factors are timed exactly to the timing of drug development phase clearance. Therefore, we are not generally concerned about whether the omission of these factors misidentifies the pipeline shocks. However, we run robustness checks for a number of potential concerns. First, we control for supplemental indications for incumbent drugs, which may increase price. Supplemental indications typically expand the number of patients that can be treated with the drug by shifting the demand curve to the right. These supplemental indications also significantly increase drug price, but previous estimates of the effect of pipeline shocks are robust to this specification. 
Table 7: Phase 3 Pipeline Shocks and Competition within Category

(1)

(2)

Variable Price Patient Out-of-Pocket

\section{Bolus Category}

Afrezza Pipeline Shock $t$

Observations

Number of drugs

$$
1.899
$$

$(1.455)$

$9,909,100$

45

$-0.521$

$(1.320)$

$3.330^{* *}$

(1.448)

2.222

$(1.652)$

$14,561,425$

41
$-0.277^{* * *}$

(0.0876)

$9,909,100$

45

Observations

Number of drugs

$0.173^{* * *}$

(0.0629)

$0.168 *$

(0.0912)

$0.395^{* * *}$

(0.0868)

$14,561,425$

41

\section{Mix Category}

Ryzodeg $\frac{70}{30}$ Pipeline Shock $_{t} \quad-1.712^{* * *}$

$0.0984^{*}$

(0.514)

Observations

$2,888,902$

$2,888,902$

Number of drugs

35

35

Note. All estimates are obtained using OLS with drug-level fixed effects. The dependent variable is provided in the column heading. Standard errors are clustered at the drug-quarter level. All regressions include health plan indicators, time trends and quarter binaries.

* Statistically significant at the 10 percent level

** Statistically significant at the 5 percent level

*** Statistically significant at the 1 percent level 
Second, we test whether the passage of the BPCI in 2010 had a significant affect on price. Previous results are also robust to this specification. Third, mail-order discounts, often for a 90-day supply, may also play a role in pricing. To test for the robustness of the price effects of pipeline shocks, we also account for whether a prescription was filled for 90 days or for 30 days. Price effects due to pipeline shocks are robust to this as well. Fourth, estimated price effects are also robust to using the medical consumer price index to adjust prices for inflation. Fifth, we also test a specification in which time trends differ at the brand-level to account for differing within-brand pricing strategy trends. Price effects of pipeline shocks are robust to this robustness check as well.

Sixth, we also consider whether pipeline shocks from earlier phases have similar effects. As previously mentioned, the vast amount of uncertainty associated with drug development likely reduces the information that an existing competitor can glean about potential competition from earlier phases. Price effects from phase 3 pipeline shocks are robust to including pipeline shocks from phase 2 and phase 1 . In addition, there are no significant price effects from phase 2 or phase 1 pipeline shocks. Seventh, we evaluate whether results are driven by outliers. Previous results are also robust to excluding outliers from the analysis, and nearly identical in both magnitude and significance. An alternative approach to considering the role of outliers would be to consider whether price responses at the median are the same as those on average, using quintile regressions with fixed effects as illustrated in Powell (2014) and Powell and Wagner (2014). Unfortunately, these methods are developed for panel data, and would require collapsing claims-level data into drug-level panel data, loosing a considerable amount of price variation. Since results are robust to the exclusion of outliers, it is unlikely that this approach will be informative. Lastly, we assess the role of Affordable Care Act (ACA) demand expansion on these price increases. Recent work by Berndt, Conti and Murphy (2017) finds both a reduction in the number of generic drug suppliers and an increase in the price of generic drugs following the implementation of the ACA. To consider this effect, we reframe time trends to include a preACA and post-ACA time trend. Using pre- and post-ACA trends magnifies the size and significance of all the pipeline shocks except for the third shock. The price effect from the third shock becomes insignificant, though remains positive. The first and final shock increase price by $\$ 2.40$ and $\$ 3.43$, respectively, and are both significant at the one percent level in this specification. Results from this specification are presented in Table 11 in the Appendix. 


\subsection{Limitations}

Despite rigorous considerations of these issues, there are other factors that may influence pricing strategies that are either not observed or not considered in our empirical analysis. Drug-level rebate size and formulary tier status, negotiated between manufacturers and payers using pharmacy benefit managers (PBMs), are key unobservables. If manufacturers truly compete over the size of the rebates to receive favorable status on formulary tiers, and not over the payments or list price of their products, then this analysis may not correctly measure the competitive effects of new branded drugs in the pipeline. Unfortunately, this information is proprietary and it is not possible to estimate drug-level measures for either of these unobservables. The database used in the analysis contains claims from over 100 payers, making it infeasible to obtain formulary tier status or rebates at the drug-level. It may be possible to back out manufacturer-level rebate sizes, but this will do little to assess the impact of rebate size or formulary status on the pricing decision. One factor that is observable but not included in the analysis is research and development (R\&D) costs. Though research and development costs can be observed at the firm level and an approximate per drug R\&D cost can be estimated as in DiMasi, Grabowski and Hansen (2016), there is no way to isolate a drug-specific $\mathrm{R} \& \mathrm{D}$ cost. In addition, it is unlikely to bias estimates on the effect of pipeline pressure. Research and development costs are sunk costs and should not be considered in the pricing decision. However, research and development costs do create a significant barrier to potential entry which thereby impacts competition and the pricing decision. Therefore, these may both be limitations of the analysis, and therefore suggest important areas of further research.

\subsection{Policy Implications for Biosimilar Drugs}

Our results suggest that potential biosimilar entry may be perceived differently than other branded therapeutic substitutes. Understanding the implications for these differences requires additional institutional details. The pricing of large molecule drugs, or biologics, like insulin may differ from pricing decisions for small molecule drugs. A biologic is a pharmaceutical drug product manufactured in, extracted from, or semi-synthesized from biological sources. These large molecule drugs are more difficult to replicate, reducing the likelihood that biosimilar entry will occur. According to the FDA, "a biosimilar is a biological product that is highly similar to and has no clinically meaningful differences from an existing FDA-approved reference product," where the reference product is a biologic already approved by the FDA. A biosimilar must demonstrate that both its structure and function are similar to the reference product. It must also demonstrate that there are "no clinically meaningful differences from the reference product in terms of safety, purity, and 
potency (safety and efficacy)." For a biosimilar to be deemed "interchangeable" with a reference product, it must meet additional requirements. Biosimilars are approved through a different abbreviated pathway that avoids duplicating costly clinical trials. However, prior to 2010, there was no regulatory pathway for biosimilar approval. The Biologics Price Competition and Innovation (BPCI) Act of 2009 was signed into law on March 23, 2010.

However, Basaglar is not approved as a biosimilar product. It was approved through an abbreviated pathway after submitting a 505(b)(2) application (Food and Drug Administration 2015). This application relied on comparisons of Basaglar and Lantus, a previously FDA-approved basal insulin, and FDA findings of safety and effectiveness for Lantus, or insulin glargine. According to the FDA, there is no insulin glargine "reference product" under license with the Public Health Service Act. It is not clear whether the manufacturer for Eli Lilly submitted a 505(b)(2) application because of this, or because studies for Basaglar began prior to the BPCI approval. In addition, Basaglar's FDA approval was delayed, due to a lawsuit filed by the manufacturer of Lantus, which alleged numerous patent infringements. ${ }^{14}$ On the other hand, Basaglar is considered a biosimilar by several European drug approval agencies. For these reasons, it would be reasonable for an existing drug manufacturer to consider this product a biosimilar as it conducted clinical trials in the pipeline. Therefore, it may also be reasonable to generalize our results as a typical response of incumbents to potential biosimilar entry.

These details highlight two important issues that inform the outlook for drug pricing with the entry of biosimilars. First, there may considerable legal battles over patent infringement for the entry of many biosimilars, which will likely encourage additional upward pressure on price. Pharmaceutical companies, both incumbents and entrants, will be incentivized to cover costs associated with funding these lawsuits by raising price. Second, it is unclear whether drug manufacturers will pursue biosimilar entry or pursue alternative abbreviated pathways, such as the 505(b)(2). Basaglar did not conduct phase 2 clinical trials, as illustrated in Table 8. If other abbreviated pathways can cut the costs of $\mathrm{R} \& \mathrm{D}$, it may be more advantageous to pursue those pathways. Finally, biosimilar entry may not be profitable if the market is saturated by enough branded biologic substitutes. It is still too early to assess whether there will be a large degree of biosimilar entry, actual or potential, and whether that competition will be enough to exert downward pressure on price. Our results seem to suggest that given the institutional structure, potential biosimilar entry or other follow-on entry could encourage incumbent drugs to increase price. However, this would require significant reconsideration, as our model demonstrating this price increase incentive is partially driven by the share

\footnotetext{
${ }^{14}$ Sanofi-Aventis US LLC et al v. Eli Lilly and Co, U.S. District Court, District of Delaware, No. 14-00884
} 
$\theta$ that switch to the new product. In the case of a biosimilar that is "interchangeable" with a reference product, a patient may be switched to the biosimiliar in part due to price. In this case, the market share loss following biosimilar entry may be greater than we assess, possibly off-setting the potential revenue gains from increasing price in the first period. For the curious reader, our model could be extended to structure $\theta$ as a function of price or copayment which could help assess the competitive effects of biosimilar entry.

\section{Conclusion}

In this study, we demonstrate both a strategic incentive for incumbent firms under patent to raise drug prices as the likelihood of competition from another brand name patented drug increases, both theoretically and empirically. Results suggest that pipeline pressure significantly increases the prices of incumbent drugs, and potential biosimilar entry may drive this effect. Specifically, prices for insulin increase by around $\$ 30$ per patient for each of the later pipeline shocks in our analysis. However, this incentive explains a little less than 10 percent of the price increases observed from 2007-2015. Therefore, there is considerable work to be done to assess the role of manufacturer-insurer bargaining power, and other important market characteristics like drug rebates and formulary tier status that likely play a role in increasing prices. Future work should also consider the differential welfare impact on patients with high deductibles and larger out-of-pocket costs and patients without insurance. 


\section{References}

Abrantes-Metz, Rosa M., Christopher P. Adams, and Albert Metz. 2004. "Pharmaceutical Development Phases: A Duration Analysis." Federal Trade Commission, Bureau of Economics Working Paper Series, Working Paper No. 274.

Aghion, Philippe, Richard Blundell, Rachel Griffith, Peter Howitt, and Susanne Prantl. 2009. "The Effects of Entry on Incumbent Innovation and Productivity." Review of Economics and Statistics, 91(1): 20-32.

Arrow, Kenneth J. 1963. "Uncertainty and the Welfare Economics of Medical Care." The American Economic Review, 53(5): 941-973.

Baumol, William J., John C. Panzar, and Robert D. Willig. 1982. Contestable Markets and the Theory of Industrial Structure. New York:Harcourt Brace Jovanovich.

Bennette, Caroline S., Catherine Richards, Sean D. Sullivan, and Scott D. Ramsey. 2016. "Steady Increase in Prices for Oral Anticancer Drugs After Market Launch Suggests a Lack of Competitive Pressure." Health Affairs, 35(5): 805-812.

Berndt, Ernst R., Rena M. Conti, and Stephen J. Murphy. 2017. "The Landscape of US Generic Prescription Drug Markets, 2004-2016.” NBER Working Paper Series, Working Paper No. 23640.

Berndt, Ernst R., Thomas G. McGuire, and Joseph P. Newhouse. 2011. "A Primer on the Economics of Prescription Pharmaceutical Pricing in Health Insurance Markets." NBER Working Paper Series, Working Paper No. 16879.

Berry, Steven T. 1992. "Estimation of a Model of Entry in the Airline Industry." Econometrica, 60(4): 889917.

Bhattacharya, Jayanta, and William B. Vogt. 2003. "A Simple Model of Pharmaceutical Price Dynamics." The Journal of Law and Economics, 46(2): 599-626.

Brekke, Kurt R., Chiara Canta, and Odd Rune Staume. 2016. "Reference pricing with endogenous generic entry." Journal of Health Economics, 50: 312-329.

Bresnahan, Timothy F., and Peter C. Reiss. 1991. "Entry Competition in Concentrated Markets." Journal of Political Economy, 99(5): 977-1009. 
Bunch, David S., and Robert Smiley. 1992. "Who Deters Entry? Evidence on the Use of Strategic Entry Deterrents." Review of Economics and Statistics, 74(3): 509-521.

Capps, Cory, David Dranove, and Mark Satterthwaite. 2003. "Competition and market power in option demand markets." RAND Journal of Economics, 34(4): 737-763.

Ching, Andrew T. 2010. "A Dynamic Oligopoly Structural Model for the Prescription Drug Market after Patent Expiration." International Economic Review, 51(4): 1175-1207.

Claxton, Gary, Matthew Raw, Michelle Long, Anthony Damico, Bradley Sawyer, Gregory Foster, Heidi Whitmore, and Lindsey Schapiro. 2016. "Employer Health Benefits: 2016 Annual Survey." The Kaiser Family Foundaiton and Health Research and Educational Trust.

Danzon, Patricia M., and Li-Wei Chao. 2000. "Does Regulation Drive Out Competition in Pharmaceutical Markets." The Journal of Law and Economics, 43(2): 311-358.

Dasgupta, P., and J.E. Stiglitz. 1988. "Potential Competition, Actual Competition, and Economic Welfare." European Economic Review, 32: 569-577.

DiMasi, J.A., L. Feldman, A. Seckler, and A. Wilson. 2010. "Trends in Risks Associated with New Drug Development: Success Rates for Investigational Drugs." Clinical Pharmacology 8 Therapeutics, 87(3): 272-277.

DiMasi, Joseph A., Henry G. Grabowski, and Ronald W. Hansen. 2016. "Innovation in the pharmaceutical industry: New estimates of R\&D costs." Journal of Health Economics, 47: 20-33.

Express Scripts. 2015. "The 2015 drug trend report."

Food and Drug Administration. 2015. "FDA approves Basaglar, the first "follow-on" insulin glargine product to treat diabetes." FDA Press Release.

Frank, Richard G., and David S. Salkever. 1997. "Generic Entry and the Pricing of Pharmaceuticals." The Journal of Economics and Management Strategy, 6(1): 75-90.

Gaynor, Martin, Carol Propper, and Stephan Seiler. 2016. "Free to Choose? Reform, choice, and consideration sets in the English National Health Service." American Economic Review, 106(11): 35213557. 
Gaynor, Martin, Kate Ho, and Robert J. Town. 2015. "The industrial organization of health-care markets." Journal of Economic Literature, 53(2): 235-284.

Generic Pharmaceutical Association. 2015. "Generic Drug Savings in the US."

Geroski, P.A. 1995. "What do we know about entry?" International Journal of Industrial Organization, 13: $421-440$.

Grabowski, Henry G., and John M. Vernon. 1992. "Brand Loyalty, Entry, and Price Competition in Pharmaceuticals after the 1984 Drug Act." The Journal of Law and Economics, 35(2): 331-350.

Hartung, Daniel M., Dennish N. Bourdette, Sharia M. Ahmed, and Ruth H. Whitman. 2015. "The cost of multiple sclerosis drugs in the US and the pharmaceutical industry." Neurology, 84: 2185-2192.

Hay, Michael, David W. Thomas, John L. Craighead, Celia Economides, and Jesse Rosenthal. 2014. "Clinical development success rates for investigational drugs." Nature Biotechnology, 32(1): 40-51.

Ho, Katherine. 2009. "Insurer-Provider Networks in the Medical Care Market." American Economic Review, 99(1): 393-430.

Ho, Katherine, and Robin S. Lee. 2017. "Equilibrium Provider Networks: Bargaining and Exclusion in Health Care Markets." NBER Working Paper No. 23742.

Howard, David H., Peter B. Bach, Ernst R. Berndt, and Rena M. Conti. 2015. "Pricing in the Market for Anticancer Drugs." Journal of Economic Perspectives, 29(1): 139-162.

Hua, Xinyang, Natalie Carvalho, Michelle Tew, Elbert S. Huang, William H. Herman, and Philip Clarke. 2016. "Expenditures and Prices of Antihyperglycemic Medications in the United States: 2002-2013." Journal of American Medical Association, 315(13): 1400-1402.

Kesselheim, Aaron S., Jerry Avorn, and Ameet Sarpatwari. 2016. "The High Cost of Prescription Drugs in the United States: Origins and Prospects for Reform." Journal of American Medical Association, 316(8): 858-871.

Kola, Ismail, and John Landis. 2004. "Can the pharmaceutical industry reduce attrition rates?" Nature Reviews: Drug Discovery, 3: 711-715.

Kyle, Margaret K. 2007. "Pharmaceutical Price Controls and Entry." The Review of Economics and Statistics, 89(1): 88-99. 
Lakdawalla, Darius, and Neeraj Sood. 2009. "Innovation and Welfare Effects of Public Drug Insurance." Journal of Public Economics, 91(1): 541-548.

Lu, Z. John, and William S. Comanor. 1998. "Strategic Pricing of New Pharmaceuticals." The Review of Economics and Statistics.

Mazzeo, Michael J. 2002. "Product choice and oligopoly market structure." RAND Journal of Economics, 33(2): 221-242.

Morton, Fiona M. Scott. 1999. "Entry decisions in the generic pharmaceutical industry." RAND Journal of Economics, 30(3): 421-440.

Nickell, Stephen J. 1996. "Competition and Corporate Performance." Journal of Political Economy, 104(4): 724-746.

Office of the Assistant Secretary for Planning and Evaluation. 2016. "ASPE Issue Brief: Observations on Trends in Prescription Drug Spending." Department of Health and Human Services.

Pakes, Ariel, Michael Ostrovsky, and Steven Berry. 2007. "Simple estimators for the parameters of discrete dynamic games (with entry/exit examples)." RAND Journal of Economics, 38(2): 373-399.

Perloff, Jeffrey M., Valerie Y Suslow, and Paul J. Seguin. 1995. "Higher Prices from Entry: Pricing of Brand-Name Drugs." Working Paper: Competition Policy Center UC Berkley, WP Number CPC99-03.

Powell, David. 2014. "Did the Economic Stimulus Payments of 2008 Reduce Labor Supply? Evidence from Quantile Panel Data Estimation." RAND Working Paper Series No. WR-710-3.

Powell, David, and Joachim Wagner. 2014. "The Exporter Productivity Premium along the Productivity Distribution: Evidence from Quantile Regression with Nonadditive Firm Fixed Effects." Review of World Economics, 150(4).

Reekie, W. Duncan. 1978. "Price and Quality Competition in the United States Drug Industry." The Journal of Industrial Economics, 26(3): 223-237.

Reiffen, David, and Michael R. Ward. 2005. "Generic Drug Industry Dynamics." Review of Economics and Statistics, 87(1): 37-49.

Rothschild, Michael, and Joseph Stiglitz. 1976. "Equilibrium in Competitive Insurance Markets: An Essay on the Economics of Imperfect Information." The Quarterly Journal of Economics, 90(4): 629-649. 
Salop, Steven C. 1979. "Strategic Entry Deterrence." American Economic Review: Papers and Proceedings of the Ninety-First Annual Meeting of the American Economic Association, 69(2): 335-338.

Santos, Rita, Hugh Gravelle, and Carol Propper. 2017. "Does Quality Affect Patients' Choice of Doctor? Evidence from England." The Economic Journal, 127: 445-494.

Selton, R. 1965. "Spieltheoretische Behandlung eines Oligopolmodells mit Nachfragetrgheit ? Teil I Bestimmung des dynamischen Preisgleichgewichts." Zeitschrift fr die gesamte Staatswissenschaft, 121: 301-324.

Tenn, Steven, and Brett W Wendling. 2014. "Entry Threats and Pricing in the Generic Drug Industry." Review of Economics and Statistics, 96(2): 214-228.

Tirole, Jean. 1988. The theory of industrial organization. MIT Press.

Yang, Wenya, Timothy M. Dall, Paul Gallo, Stacey L. Kowal, and Paul F. Hogan. 2013. "Economic Costs of Diabetes in the U.S. in 2012." Diabetes Care, 36: 1033-1046. 


\section{A Appendix}

\section{A.1 Derivations and Proofs}

The following solution describes the steps used to obtain the entrant's best response function in Equation 4 .

$$
\begin{aligned}
& F O C P_{2 e}: \frac{\partial R_{e}}{\partial P_{2 e}}=\left[a-b_{1} c_{2 e}+b_{2} c_{2 i}\right]+P_{2 e} \cdot-b_{1} \frac{c_{2 e}}{P_{2 e}}=0 \\
& a-b_{1} c_{2 e}+b_{2} c_{2 i}-P_{2 e} \cdot b_{1} \frac{c_{1 i}}{P_{1 i}}=0 \text { (Using Lemma ?? and Assumption } 4) \\
& a-b_{1}\left(\frac{c_{1 i}}{P_{1 i}} P_{2 e}\right)+b_{2} c_{2 i}-b_{1} \frac{c_{1 i}}{P_{1 i}} P_{2 e}=0\left(\text { Using } c_{2 e}=\frac{c_{1 i}}{P_{1 i}} P_{2 e}\right) \\
& \theta Q+c_{2 i}\left(b_{1}-b_{2}\right)-2 b_{1} \frac{c_{1 i}}{P_{1 i}} P_{2 e}+b_{2} c_{2 i}=0 \text { (Replacing a from } 2) \\
& \theta Q+\frac{c_{1 i}}{P_{1 i}} P_{2 i}\left(b_{1}-b_{2}\right)-2 b_{1} \frac{c_{1 i}}{P_{1 i}} P_{2 e}+b_{2} \frac{c_{1 i}}{P_{1 i}} P_{2 i}=0\left(\text { Using } c_{2 i}=\frac{c_{1 i}}{P_{1 i}} P_{2 i}\right) \\
& \theta Q+b_{1} \frac{c_{1 i}}{P_{1 i}} P_{2 i}-2 b_{1} \frac{c_{1 i}}{P_{1 i}} P_{2 e}=0 \text { (Simplifying) } \\
& \frac{\theta Q P_{1 i}}{2 b_{1} c_{1 i}}+\frac{1}{2} P_{2 i}\left.=P_{2 e} \text { (Solving for } P_{2 e}\right) \\
& P_{2 e}=\frac{\theta Q P_{1 i}}{2 b_{1} c_{1 i}}+\frac{1}{2} P_{2 i}
\end{aligned}
$$

The following solution describes the steps used to obtain the incumbent's simplified second period maximization problem in Equation 9.

$$
\begin{aligned}
\max P_{2 i} \cdot Q_{2 i} & =P_{2 i} \cdot\left[\alpha-\beta_{1} c_{2 i}+\beta_{2} c_{2 e}\right] \\
& =P_{2 i} \cdot\left[\alpha-\beta_{1} \frac{c_{1 i}}{P_{1 i}} P_{2 i}+\beta_{2} \frac{c_{1 i}}{P_{1 i}} P_{2 e}\right]\left(\text { Using } c_{2 i}=\frac{c_{1 i}}{P_{1 i}} P_{2 i} \text { and } c_{2 e}=\frac{c_{1 i}}{P_{1 i}} P_{2 e}\right) \\
& =P_{2 i} \cdot\left[\alpha-\beta_{1} \frac{c_{1 i}}{P_{1 i}} P_{2 i}+\beta_{2} \frac{c_{1 i}}{P_{1 i}}\left(\frac{\theta Q P_{1 i}}{2 b_{1} c_{1 i}}+\frac{1}{2} P_{2 i}\right)\right] \text { (Using the entrant's best response from Equation ??) } \\
& =P_{2 i} \cdot\left[\alpha-\beta_{1} \frac{c_{1 i}}{P_{1 i}} P_{2 i}+\beta_{2} \frac{c_{1 i}}{P_{1 i}}\left(\frac{\theta Q P_{1 i}}{2 b_{1} c_{1 i}}+\frac{1}{2} P_{2 i}\right)\right] \text { (Simplifying) }
\end{aligned}
$$


The following solution describes the steps used to obtain the incumbent's best response function in Equation 11.

$$
\begin{aligned}
& F O C P_{2 i}: \frac{\partial R_{i}}{\partial P_{2 i}}=\left[\alpha-\beta_{1} \frac{c_{1 i}}{P_{1 i}} P_{2 i}+\beta_{2} \frac{c_{1 i}}{P_{1 i}}\left(\frac{\theta Q P_{1 i}}{2 b_{1} c_{1 i}}+\frac{1}{2} P_{2 i}\right)\right]+ \\
& P_{2 i} \cdot\left[-\beta_{1} \frac{c_{1 i}}{P_{1 i}}+\beta_{2} \frac{c_{1 i}}{P_{1 i}}\left(\frac{1}{2}\right)\right]=0 \\
& \alpha-2 \beta_{1} \frac{c_{1 i}}{P_{1 i}} P_{2 i}+\beta_{2} \frac{\theta Q}{2 b_{1}}+\beta_{2} \frac{c_{1 i}}{P_{1 i}} P_{2 i}=0 \text { (Simplifying) } \\
& \alpha+\beta_{2} \frac{\theta Q}{2 b_{1}}=2 \beta_{1} \frac{c_{1 i}}{P_{1 i}} P_{2 i}-\beta_{2} \frac{c_{1 i}}{P_{1 i}} P_{2 i} \\
& \alpha+\beta_{2} \frac{\theta Q}{2 b_{1}}=\frac{c_{1 i}}{P_{1 i}}\left(2 \beta_{1}-\beta_{2}\right) P_{2 i} \\
& \alpha+\beta_{2} \frac{\theta Q}{2 b_{1}}=P_{2 i} \\
& P_{1 i} \frac{\alpha}{c_{1 i}\left(2 \beta_{1}-\beta_{2}\right)} \\
& P_{2 i}=P_{1 i} \frac{\alpha+\beta_{2} \frac{\theta Q}{2 b_{1}}}{c_{1 i}\left(2 \beta_{1}-\beta_{2}\right)}
\end{aligned}
$$

The following solution describes the steps used to obtain a simplified version of the incumbent's two period decision problem in Equation 12

$$
\begin{aligned}
\max _{P_{1 i}} R_{i} & =P_{1 i} \cdot Q_{1 i}+\left[(1-\rho) P_{1 i} \cdot Q_{1 i}+\rho P_{2 i} \cdot Q_{2 i}\right] \\
& =P_{1 i} \cdot\left(\alpha-\beta_{1} \cdot c_{1 i}\right)+(1-\rho) P_{1 i} \cdot\left(\alpha-\beta_{1} \cdot c_{1 i}\right)+\rho P_{2 i}\left(\alpha-\beta_{1} c_{2 i}+\beta_{2} c_{2 e}\right) \\
& =P_{1 i} \cdot\left(\alpha-\beta_{1} \cdot c_{1 i}\right)+(1-\rho) P_{1 i} \cdot\left(\alpha-\beta_{1} \cdot c_{1 i}\right)+\rho \omega \frac{P_{1 i}}{c_{1 i}}\left(\alpha-\beta_{1} c_{2 i}+\beta_{2} c_{2 e}\right) \\
& \left(\text { Replacing } P_{2 i}=\omega \frac{P_{1 i}}{c_{1 i}}\right) \\
& =P_{1 i} \cdot\left(\alpha-\beta_{1} \cdot c_{1 i}\right)+(1-\rho) P_{1 i} \cdot\left(\alpha-\beta_{1} \cdot c_{1 i}\right)+\rho \omega \frac{P_{1 i}}{c_{1 i}}\left(\alpha-\beta_{1} \frac{c_{1 i}}{P_{1 i}} P_{2 i}+\beta_{2} \frac{c_{1 i}}{P_{1 i}} P_{2 e}\right) \\
& \left(\mathrm{U} \operatorname{sing} c_{2 i}=\frac{c_{1 i}}{P_{1 i}} P_{2 i} \text { and } c_{2 e}=\frac{c_{1 i}}{P_{1 i}} P_{2 e}\right) \\
& =P_{1 i} \cdot\left(\alpha-\beta_{1} \cdot c_{1 i}\right)+(1-\rho) P_{1 i} \cdot\left(\alpha-\beta_{1} \cdot c_{1 i}\right)+\rho \omega \frac{P_{1 i}}{c_{1 i}}\left(\alpha-\beta_{1} \frac{c_{1 i}}{P_{1 i}} P_{2 i}+\beta_{2} \frac{c_{1 i}}{P_{1 i}}\left[\frac{\theta Q P_{1 i}}{2 b_{1} c_{1 i}}+\frac{1}{2} P_{2 i}\right]\right)
\end{aligned}
$$

(Using the Entrant's BR)

$=P_{1 i} \cdot\left(\alpha-\beta_{1} \cdot c_{1 i}\right)+(1-\rho) P_{1 i} \cdot\left(\alpha-\beta_{1} \cdot c_{1 i}\right)+\rho \omega \frac{P_{1 i}}{c_{1 i}}\left(\alpha-\beta_{1} \frac{c_{1 i}}{P_{1 i}} \omega \frac{P_{1 i}}{c_{1 i}}+\beta_{2} \frac{c_{1 i}}{P_{1 i}}\left[\frac{\theta Q P_{1 i}}{2 b_{1} c_{1 i}}+\frac{1}{2} \omega \frac{P_{1 i}}{c_{1 i}}\right]\right)$

(Using $P_{2 i}=\omega \frac{P_{1 i}}{c_{1 i}}$ )

$=P_{1 i} \cdot\left(\alpha-\beta_{1} \cdot c_{1 i}\right)+(1-\rho) P_{1 i} \cdot\left(\alpha-\beta_{1} \cdot c_{1 i}\right)+\rho \omega \frac{P_{1 i}}{c_{1 i}}\left(\alpha-\beta_{1} \omega+\beta_{2}\left[\frac{\theta Q}{2 b_{1}}+\frac{1}{2} \omega\right]\right)$

(Simplifying) 
The following solution describes the steps used to obtain Equation 14.

$$
\begin{aligned}
& F O C_{P_{1 i}}: \frac{\partial R_{i}}{\partial P_{1 i}}=\left(\alpha-\beta_{1} c_{1 i}\right)+P_{1 i}\left(-\beta_{1} \frac{c_{1 i}}{P_{1 i}}\right)+(1-\rho)\left[\left(\alpha-\beta_{1} c_{1 i}\right)+P_{1 i}\left(-\beta_{1} \frac{c_{1 i}}{P_{1 i}}\right)\right] \\
&+\rho \omega\left(\alpha-\beta_{1} \omega+\beta_{2}\left[\frac{\theta Q}{2 b_{1}}+\frac{1}{2} \omega\right]\right)\left(\frac{c_{1 i}-P_{1 i} \frac{c_{1 i}}{P_{1 i}}}{c_{1 i}^{2}}\right)=0 \\
& \alpha-2 \beta_{1} c_{1 i}+(1-\rho)\left(\alpha-2 \beta_{1} c_{1 i}\right)+\rho \omega\left(\alpha-\beta_{1} \omega+\beta_{2}\left[\frac{\theta Q}{2 b_{1}}+\frac{1}{2} \omega\right]\right)\left(\frac{0}{c_{1 i}^{2}}\right)=0 \\
& \alpha-2 \beta_{1} c_{1 i}+(1-\rho)\left(\alpha-2 \beta_{1} c_{1 i}\right)=0 \\
& 2 \alpha-4 \beta_{1} c_{1 i}-\alpha \rho+\rho 2 \beta_{1} c_{1 i}=0
\end{aligned}
$$

The following solution describes the steps using implicit function differentiation to derive the condition presented in Equation 15.

$$
\frac{\mathrm{d} P_{1 i}}{\mathrm{~d} \rho}=\frac{-4 \beta_{1} \frac{c_{1 i}}{P_{1 i}}+\rho 2 \beta_{1} \frac{c_{1 i}}{P_{1 i}}}{-\alpha+2 \beta_{1} c_{1 i}}=\frac{2 \beta_{1} \frac{c_{1 i}}{P_{1 i}}(\rho-2)}{2 \beta_{1} c_{1 i}-\alpha}
$$

The following solution describes the method used to solve for a range of elasticities for which the incumbent has an incentive to increase price prior to entry.

$$
\begin{gathered}
\varepsilon=\frac{\beta_{1} c_{1 i}}{\alpha-\beta_{1} c_{1 i}}<y \\
\beta_{1} c_{1 i}<y\left(\alpha-\beta_{1} c_{1 i}\right) \\
(y+1) \beta_{1} c_{1 i}<y \alpha \\
\frac{y+1}{y} \beta_{1} c_{1 i}-\alpha<0
\end{gathered}
$$

To find the range of elasticities for which $2 \beta_{1} c_{1 i}-\alpha<0$, simply solve for y by setting $\frac{y+1}{y}=2$. This inequality will be satisfied when $\varepsilon=1$. In fact, it will be satisfied as long as $|\varepsilon| \leq 1$. 
Table 8: Clinical Trial Details for Drugs in Development

\begin{tabular}{|c|c|c|c|c|}
\hline Brand Name & Trial Label from Med Review & NCT ID & Phase & Study Start \\
\hline Afrezza & PDC-INS-0002 & NCT00511979 & 1 & Aug-99 \\
\hline Afrezza & MKC-TI-015 & NCT01021891 & 1 & Jul-06 \\
\hline Afrezza & MKC-TI-017 & NCT00626249 & 1 & Aug-07 \\
\hline Afrezza & & NCT00642538 & 1 & Feb-08 \\
\hline Afrezza & MKC-TI-131 & NCT00721344 & 1 & Apr-08 \\
\hline Afrezza & MKC-TI-113 & NCT00673621 & 1 & May-08 \\
\hline Afrezza & MKC-TI-114 & NCT00674050 & 1 & May-08 \\
\hline Afrezza & MKC-TI-122 & NCT00757367 & 1 & Jul-08 \\
\hline Afrezza & MKC-TI-167 & NCT01365117 & 1 & Jan-11 \\
\hline Afrezza & MKC-TI-176 & NCT01490762 & 1 & Dec-11 \\
\hline Afrezza & MKC-TI-177 & NCT01544881 & 1 & Mar-12 \\
\hline Afrezza & MKC-TI-178 & NCT01902121 & 1 & Aug-13 \\
\hline Afrezza & MKC-TI-179 & NCT01982604 & 1 & Nov-13 \\
\hline Afrezza & & NCT02470637 & 1 & Jun-15 \\
\hline Afrezza & & NCT02485327 & 1 & Jul-15 \\
\hline Afrezza & MKC-TI-138 & & 1 & \\
\hline Afrezza & MKC-TI-03B & NCT00419302 & 2 & Oct-03 \\
\hline Afrezza & PDC-INS-0008 & NCT00511602 & 2 & Dec-03 \\
\hline Afrezza & MKC-TI-003B2 & NCT00511719 & 2 & Feb-04 \\
\hline Afrezza & MKC-TI-010 & NCT00754624 & 2 & May-04 \\
\hline Afrezza & MKC-TI-005 & NCT00511732 & 2 & Jun-04 \\
\hline Afrezza & MKC-TI-016 & NCT00934414 & 2 & Aug-04 \\
\hline Afrezza & MKC-TI-101 & NCT00539396 & 2 & Mar-05 \\
\hline Afrezza & MKC-TI-118 & NCT00570687 & 2 & Sep-07 \\
\hline Afrezza & MKC-TI-112 & NCT00642681 & 2 & Dec-07 \\
\hline Afrezza & MKC-TI-116 & NCT00662857 & 2 & Apr-08 \\
\hline Afrezza & MKC-TI-119 & NCT00747006 & 2 & Sep-08 \\
\hline Afrezza & MKC-TI-026 & & 2 & \\
\hline Afrezza & MKC-TI-103 & NCT00332488 & 3 & Dec-04 \\
\hline Afrezza & MKC-TI-030 & NCT00308737 & 3 & Jun-05 \\
\hline Afrezza & MKC-TI-014 & NCT00539890 & 3 & Nov-05 \\
\hline Afrezza & MKC-TI-009 & NCT00308308 & 3 & Feb-06 \\
\hline Afrezza & MKC-TI-102 & NCT00309244 & 3 & Feb-06 \\
\hline Afrezza & MKC-TI-105 & NCT00332826 & 3 & Jun-06 \\
\hline Afrezza & MKC-TI-126 & NCT00741429 & 3 & May-07 \\
\hline Afrezza & MKC-TI-117 & NCT00700622 & 3 & May-08 \\
\hline Afrezza & MKC-TI-139 & NCT01798914 & 3 & Oct-08 \\
\hline Afrezza & MKC-TI-162 & NCT01196104 & 3 & Sep-10 \\
\hline Afrezza & MKC-TI-164 & NCT01201928 & 3 & Oct-10 \\
\hline Afrezza & MKC-TI-171 & NCT01445951 & 3 & Sep-11 \\
\hline Afrezza & MKC-TI-175 & NCT01451398 & 3 & Nov-11 \\
\hline Afrezza & MKC-129 & - & - & \\
\hline Afrezza & MKC-143 & - & - & \\
\hline Afrezza & MKC-TI-025 & - & - & \\
\hline Afrezza & MKC-TI-027 & - & - & \\
\hline Afrezza & MKC-TI-104 & - & - & \\
\hline Afrezza & MKC-TI-110 & - & - & \\
\hline Afrezza & MKC-TI-111 & - & - & \\
\hline
\end{tabular}




\begin{tabular}{|c|c|c|c|c|}
\hline Brand Name & Trial Label from Med Review & NCT ID & Phase & Study Start \\
\hline Afrezza & MKC-TI-123 & - & - & \\
\hline Afrezza & MKC-TI-140 & - & - & \\
\hline Afrezza & MKC-TI-141 & - & - & \\
\hline Afrezza & MKC-TI-142 & - & - & \\
\hline Afrezza & MKC-TI-159 & - & - & \\
\hline Afrezza & PDC-INS-0001 & - & - & \\
\hline Afrezza & PDC-INS-0001A & - & - & \\
\hline Afrezza & PDC-INS-0001B & - & - & \\
\hline Afrezza & PDC-INS-0001C & - & - & \\
\hline Afrezza & PDC-INS-0002A & & - & \\
\hline Afrezza & PDC-INS-0003 & - & - & \\
\hline Afrezza & PDC-INS-0003A & - & - & \\
\hline Afrezza & PDC-INS-0004 & - & - & \\
\hline Afrezza & PDC-INS-0004A & - & - & \\
\hline Afrezza & PDC-INS-0006 & - & - & \\
\hline Afrezza & PDC-INS-0007 & - & - & \\
\hline Afrezza & PDC-INS-0011 & - & - & \\
\hline Afrezza & & & NDA Submission & Mar-09 \\
\hline Basaglar & ABEI & NCT01374178 & 1 & Jun-11 \\
\hline Basaglar & ABEA & NCT01476345 & 1 & Nov-11 \\
\hline Basaglar & ABEE & NCT01600950 & 1 & May-12 \\
\hline Basaglar & ABEM & NCT01634165 & 1 & Jul-12 \\
\hline Basaglar & ABEO & NCT01688635 & 1 & Sep-12 \\
\hline Basaglar & ABEV & NCT02955953 & 1 & Nov-16 \\
\hline Basaglar & ABEN & & 1 & \\
\hline Basaglar & ABEB & NCT01421147 & 3 & Aug-11 \\
\hline Basaglar & ABEC & NCT01421459 & 3 & Sep-11 \\
\hline Basaglar & ABER & NCT02302716 & 3 & Dec-14 \\
\hline Basaglar & & & NDA Submission & Oct-13 \\
\hline Toujeo & PKD11627 & NCT01195454 & 1 & Aug-10 \\
\hline Toujeo & TDR11626 & NCT01349855 & 1 & Mar-11 \\
\hline Toujeo & PKD12270 & NCT01493115 & 1 & Nov-11 \\
\hline Toujeo & PDY12335 & NCT01676233 & 1 & Sep-12 \\
\hline Toujeo & PKD13560 & NCT01838083 & 1 & Apr-13 \\
\hline Toujeo & & NCT02536859 & 1 & Aug-15 \\
\hline Toujeo & PDY12777 & NCT01658579 & 2 & Aug-12 \\
\hline Toujeo & EFC11628 & NCT01499082 & 3 & Dec-11 \\
\hline Toujeo & EFC11629 & NCT01499095 & 3 & Dec-11 \\
\hline Toujeo & EFC12347 & NCT01676220 & 3 & Aug-12 \\
\hline Toujeo & EFC12449 & NCT01689129 & 3 & Sep-12 \\
\hline Toujeo & EFC12456 & NCT01683266 & 3 & Sep-12 \\
\hline Toujeo & EFC12512 & NCT01689142 & 3 & Sep-12 \\
\hline Toujeo & PDY14065 & NCT02227212 & 3 & Aug-14 \\
\hline Toujeo & EFC13799 & NCT02320721 & 3 & Jan-15 \\
\hline Toujeo & & NCT02401243 & 3 & Mar-15 \\
\hline Toujeo & EFC13470 & NCT02585674 & 3 & Dec-15 \\
\hline Toujeo & EFC13957 & NCT02735044 & 3 & Apr-16 \\
\hline Toujeo & EFC12814 & NCT02855684 & 3 & Aug-16 \\
\hline Toujeo & & & NDA Submission & Apr-14 \\
\hline
\end{tabular}




\begin{tabular}{|c|c|c|c|c|}
\hline Brand Name & Trial Label from Med Review & NCT ID & Phase & Study Start \\
\hline Toujeo & PKD10086 & & & \\
\hline Tresiba & 1876 & NCT01868529 & 1 & Jan-08 \\
\hline Tresiba & 1991 & NCT00961324 & 1 & Jul-09 \\
\hline Tresiba & 1988 & NCT00966368 & 1 & Aug-09 \\
\hline Tresiba & 1989 & NCT00976326 & 1 & Aug-09 \\
\hline Tresiba & 1994 & NCT00964418 & 1 & Aug-09 \\
\hline Tresiba & 3765 & NCT00964964 & 1 & Aug-09 \\
\hline Tresiba & 1977 & NCT00992537 & 1 & Oct-09 \\
\hline Tresiba & 3538 & NCT01002768 & 1 & Oct-09 \\
\hline Tresiba & 1990 & NCT01006057 & 1 & Nov-09 \\
\hline Tresiba & 1995 & NCT01030926 & 1 & Dec-09 \\
\hline Tresiba & 3762 & NCT01043510 & 1 & Jan-10 \\
\hline Tresiba & 3678 & NCT01076634 & 1 & Feb-10 \\
\hline Tresiba & 1993 & NCT01114542 & 1 & May-10 \\
\hline Tresiba & 1987 & NCT01154881 & 1 & Jun-10 \\
\hline Tresiba & 1992 & NCT01151072 & 1 & Jun-10 \\
\hline Tresiba & 1996 & NCT01135927 & 1 & Jun-10 \\
\hline Tresiba & 3857 & NCT01173926 & 1 & Jul-10 \\
\hline Tresiba & 3769 & NCT01193387 & 1 & Aug-10 \\
\hline Tresiba & 1999 & NCT01437592 & 1 & Sep-11 \\
\hline Tresiba & 4000 & NCT01623375 & 1 & Jun-12 \\
\hline Tresiba & 3999 & NCT01704417 & 1 & Oct-12 \\
\hline Tresiba & 4227 & NCT02536859 & 1 & Aug-15 \\
\hline Tresiba & 1835 & NCT00612040 & 2 & Jan-08 \\
\hline Tresiba & 1836 & NCT00611884 & 2 & Jan-08 \\
\hline Tresiba & 3569 & NCT00841087 & 2 & Jan-09 \\
\hline Tresiba & 3579 & NCT00982644 & 3 & Sep-09 \\
\hline Tresiba & 3582 & NCT00972283 & 3 & Sep-09 \\
\hline Tresiba & 3583 & NCT00982228 & 3 & Sep-09 \\
\hline Tresiba & 3668 & NCT01006291 & 3 & Nov-09 \\
\hline Tresiba & 3580 & NCT01046110 & 3 & Jan-10 \\
\hline Tresiba & 3585 & NCT01074268 & 3 & Feb-10 \\
\hline Tresiba & 3586 & NCT01059799 & 3 & Feb-10 \\
\hline Tresiba & 3724 & NCT01068678 & 3 & Feb-10 \\
\hline Tresiba & 3672 & NCT01068665 & 3 & Mar-10 \\
\hline Tresiba & 3718 & NCT01076647 & 3 & Mar-10 \\
\hline Tresiba & 3770 & NCT01079234 & 3 & Mar-10 \\
\hline Tresiba & 3839 & NCT01135992 & 3 & Jun-10 \\
\hline Tresiba & 3846 & NCT01326026 & 3 & Mar-11 \\
\hline Tresiba & 3923 & NCT01364428 & 3 & Jun-11 \\
\hline Tresiba & 3948 & NCT01388361 & 3 & Sep-11 \\
\hline Tresiba & 3561 & NCT01513473 & 3 & Jan-12 \\
\hline Tresiba & 3874 & NCT01569841 & 3 & Apr-12 \\
\hline Tresiba & 3943 & NCT01570751 & 3 & Apr-12 \\
\hline Tresiba & 3944 & NCT01664247 & 3 & Oct-12 \\
\hline Tresiba & 3587 & NCT01849289 & 3 & Jun-13 \\
\hline
\end{tabular}




\begin{tabular}{|c|c|c|c|c|}
\hline Brand Name & Trial Label from Med Review & NCT ID & Phase & Study Start \\
\hline Tresiba & 4060 & NCT01880736 & 3 & Jun-13 \\
\hline Tresiba & 3995 & NCT02034513 & 3 & Jan-14 \\
\hline Tresiba & 3998 & NCT02030600 & 3 & Jan-14 \\
\hline Tresiba & & & NDA Submission & Sep-11 \\
\hline Ryzodeg70/30 & 1718 & NCT01865279 & 1 & Dec-05 \\
\hline Ryzodeg70/30 & 1719 & NCT01865292 & 1 & Aug-06 \\
\hline Ryzodeg70/30 & 1738 & NCT01865305 & 1 & Sep-06 \\
\hline Ryzodeg70/30 & 1740 & NCT01865318 & 1 & Sep-06 \\
\hline Ryzodeg70/30 & 1788 & NCT01865331 & 1 & Dec-06 \\
\hline Ryzodeg70/30 & 1790 & NCT01868555 & 1 & Dec-07 \\
\hline Ryzodeg70/30 & 1959 & NCT01868568 & 1 & Apr-08 \\
\hline Ryzodeg70/30 & 1985 & NCT01868581 & 1 & May-08 \\
\hline Ryzodeg70/30 & 3539 & NCT00993096 & 1 & Sep-09 \\
\hline Ryzodeg70/30 & 1977 & NCT00992537 & 1 & Oct-09 \\
\hline Ryzodeg70/30 & 1983 & NCT01051102 & 1 & Jan-10 \\
\hline Ryzodeg70/30 & 1978 & NCT01134224 & 1 & May-10 \\
\hline Ryzodeg70/30 & 1980 & NCT01125553 & 1 & May-10 \\
\hline Ryzodeg70/30 & 1982 & NCT01138488 & 1 & Jun-10 \\
\hline Ryzodeg70/30 & 3857 & NCT01173926 & 1 & Jul-10 \\
\hline Ryzodeg70/30 & 1981 & NCT01174303 & 1 & Aug-10 \\
\hline Ryzodeg70/30 & 3834 & NCT01455142 & 1 & Oct-11 \\
\hline Ryzodeg70/30 & 1979 & NCT01590836 & 1 & Apr-12 \\
\hline Ryzodeg70/30 & 1984 & NCT02844790 & 1 & Jul-16 \\
\hline Ryzodeg70/30 & 1791 & NCT00614055 & 2 & Jan-08 \\
\hline Ryzodeg70/30 & 1792 & NCT00613951 & 2 & Jan-08 \\
\hline Ryzodeg70/30 & 3570 & NCT00842361 & 2 & Jan-09 \\
\hline Ryzodeg70/30 & 3594 & NCT00978627 & 3 & Aug-09 \\
\hline Ryzodeg70/30 & 3592 & NCT01009580 & 3 & Nov-09 \\
\hline Ryzodeg70/30 & 3590 & NCT01045707 & 3 & Jan-10 \\
\hline Ryzodeg70/30 & 3593 & NCT01045447 & 3 & Jan-10 \\
\hline Ryzodeg70/30 & 3597 & NCT01059812 & 3 & Feb-10 \\
\hline Ryzodeg70/30 & 3896 & NCT01272193 & 3 & Jan-11 \\
\hline Ryzodeg70/30 & 3844 & NCT01365507 & 3 & Jun-11 \\
\hline Ryzodeg70/30 & 3940 & NCT01513590 & 3 & Jan-12 \\
\hline Ryzodeg70/30 & 3941 & NCT01680341 & 3 & Aug-12 \\
\hline Ryzodeg70/30 & 3996 & NCT01713530 & 3 & Feb-13 \\
\hline Ryzodeg70/30 & 4003 & NCT01814137 & 3 & Mar-13 \\
\hline Ryzodeg70/30 & 3816 & NCT01835431 & 3 & Oct-13 \\
\hline Ryzodeg70/30 & 4243 & NCT02648217 & 3 & Jan-16 \\
\hline Ryzodeg70/30 & 3598 & NCT02762578 & 3 & May-16 \\
\hline Ryzodeg70/30 & 4266 & NCT02906917 & 3 & Sep-16 \\
\hline Ryzodeg70/30 & & & NDA Submission & Sep-11 \\
\hline
\end{tabular}


Table 9: National Drug Codes Insulin Claims

\begin{tabular}{|c|c|c|}
\hline National Drug Code (NDC) & Proprietary Name & Manufacturer \\
\hline 00002751001 & HUMALOG & Eli Lilly \& Company \\
\hline 00002751017 & HUMALOG & Eli Lilly \& Company \\
\hline 00002751101 & HUMALOG MIX $75 / 25$ & Eli Lilly \& Company \\
\hline 00002751201 & HUMALOG MIX 50/50 & Eli Lilly \& Company \\
\hline 00002751559 & HUMALOG & Eli Lilly \& Company \\
\hline 00002751601 & HUMALOG & Eli Lilly \& Company \\
\hline 00002751659 & HUMALOG & Eli Lilly \& Company \\
\hline 00002771227 & HUMALOG & Eli Lilly \& Company \\
\hline 00002811001 & ILETIN PZI & Eli Lilly \& Company \\
\hline 00002811101 & ILETIN II PZI PORK & Eli Lilly \& Company \\
\hline 00002811201 & ILETIN II PZI BEEF & Eli Lilly \& Company \\
\hline 00002814001 & ILETIN PZI & Eli Lilly \& Company \\
\hline 00002821001 & ILETIN REGULAR I & Eli Lilly \& Company \\
\hline 00002821101 & ILETIN II REGULAR PORK & Eli Lilly \& Company \\
\hline 00002821201 & ILETIN II REG. BEEF & Eli Lilly \& Company \\
\hline 00002821501 & HUMULIN R & Eli Lilly \& Company \\
\hline 00002821517 & HUMULIN R & Eli Lilly \& Company \\
\hline 00002821591 & RELION HUMULIN R & Eli Lilly \& Company \\
\hline 00002821601 & HUMULIN BR & Eli Lilly \& Company \\
\hline 00002821759 & HUMULIN R & Eli Lilly \& Company \\
\hline 00002824001 & ILETIN REGULAR I & Eli Lilly \& Company \\
\hline 00002831001 & ILETIN NPH I & Eli Lilly \& Company \\
\hline 00002831101 & ILETIN II NPH PORK & Eli Lilly \& Company \\
\hline 00002831201 & ILETIN II NPH BEEF & Eli Lilly \& Company \\
\hline 00002831501 & HUMULIN N & Eli Lilly \& Company \\
\hline 00002831517 & HUMULIN N & Eli Lilly \& Company \\
\hline 00002831591 & RELION HUMULIN N & Eli Lilly \& Company \\
\hline 00002831759 & HUMULIN N & Eli Lilly \& Company \\
\hline 00002834001 & ILETIN NPH I & Eli Lilly \& Company \\
\hline 00002841001 & ILETIN LENTE I & Eli Lilly \& Company \\
\hline 00002841101 & ILETIN II LENTE PORK & Eli Lilly \& Company \\
\hline 00002841201 & ILETIN II LENTE BEEF & Eli Lilly \& Company \\
\hline 00002841501 & HUMULIN L & Eli Lilly \& Company \\
\hline 00002844001 & ILETIN LENTE I & Eli Lilly \& Company \\
\hline 00002850001 & ILETIN II REGULAR PORK & Eli Lilly \& Company \\
\hline 00002850101 & HUMULIN R CONCENTRATED U-500 & Eli Lilly \& Company \\
\hline 00002851001 & ILETIN SEMILENTE & Eli Lilly \& Company \\
\hline 00002854001 & ILETIN SEMILENTE & Eli Lilly \& Company \\
\hline 00002861001 & ILETIN ULTRALENTE & Eli Lilly \& Company \\
\hline 00002861501 & HUMULIN U & Eli Lilly \& Company \\
\hline 00002864001 & ILETIN ULTRALENTE & Eli Lilly \& Company \\
\hline 00002871501 & HUMULIN 70/30 & Eli Lilly \& Company \\
\hline 00002871517 & HUMULIN 70/30 & Eli Lilly \& Company \\
\hline 00002871591 & RELION HUMULIN 70/30 & Eli Lilly \& Company \\
\hline 00002871759 & HUMULIN 70/30 & Eli Lilly \& Company \\
\hline 00002872559 & HUMALOG PEN & Eli Lilly \& Company \\
\hline 00002873001 & HUMULIN N PEN & Eli Lilly \& Company \\
\hline 00002873059 & HUMULIN N PEN & Eli Lilly \& Company \\
\hline
\end{tabular}




\begin{tabular}{|c|c|c|}
\hline National Drug Code (NDC) & Proprietary Name & Manufacturer \\
\hline 00002877001 & HUMULIN 70/30 PEN & Eli Lilly \& Company \\
\hline 00002877059 & HUMULIN 70/30 PEN & Eli Lilly \& Company \\
\hline 00002879359 & HUMALOG MIX 50/50 & Eli Lilly \& Company \\
\hline 00002879459 & HUMALOG MIX 75/25 PEN & Eli Lilly \& Company \\
\hline 00002879701 & HUMALOG MIX $75 / 25$ & Eli Lilly \& Company \\
\hline 00002879759 & HUMALOG MIX $75 / 25$ & Eli Lilly \& Company \\
\hline 00002879801 & HUMALOG MIX 50/50 & Eli Lilly \& Company \\
\hline 00002879859 & HUMALOG MIX 50/50 & Eli Lilly \& Company \\
\hline 00002879901 & HUMALOG & Eli Lilly \& Company \\
\hline 00002879959 & HUMALOG & Eli Lilly \& Company \\
\hline 00002880359 & HUMULIN 70/30 KWIKPEN & Eli Lilly \& Company \\
\hline 00002880559 & HUMULIN N KWIKPEN & Eli Lilly \& Company \\
\hline 00002951501 & HUMULIN 50/50 & Eli Lilly \& Company \\
\hline 00003183310 & NOVOLIN R & Novo Nordisk Inc \\
\hline 00003183315 & NOVOLIN R & Novo Nordisk Inc \\
\hline 00003183410 & NOVOLIN N & Novo Nordisk Inc \\
\hline 00003183415 & NOVOLIN N PENFILL & Novo Nordisk Inc \\
\hline 00003183510 & NOVOLIN L & Novo Nordisk Inc \\
\hline 00003183710 & NOVOLIN $70 / 30$ & Novo Nordisk Inc \\
\hline 00003183715 & NOVOLIN 70/30 PENFILL & Novo Nordisk Inc \\
\hline 00003244110 & INSULIN, PURIFIED SEMILENTE PORK & Novo Nordisk Inc \\
\hline 00003244510 & INSULIN, PURIFIED ULTRALENTE BEEF & Novo Nordisk Inc \\
\hline 00003352115 & INSULIN & Squibb-Novo Inc \\
\hline 00024586903 & TOUJEO & Sanofi-Aventis US LLC \\
\hline 00024587490 & AFREZZA & Sanofi-Aventis US LLC \\
\hline 00024588236 & AFREZZA & Sanofi-Aventis US LLC \\
\hline 00024588463 & AFREZZA & Sanofi-Aventis US LLC \\
\hline 00024589463 & AFREZZA & Sanofi-Aventis US LLC \\
\hline 00069005019 & EXUBERA COMBINATION PACK 12 & Pfizer \\
\hline 00069005053 & EXUBERA COMBINATION PACK 15 & Pfizer \\
\hline 00069005085 & EXUBERA KIT & Pfizer \\
\hline 00069070737 & EXUBERA & Pfizer \\
\hline 00069072437 & EXUBERA & Pfizer \\
\hline 00088221905 & LANTUS SOLOSTAR & Sanofi-Aventis US LLC \\
\hline 00088222033 & LANTUS & Sanofi-Aventis US LLC \\
\hline 00088222052 & LANTUS & Sanofi-Aventis US LLC \\
\hline 00088222060 & LANTUS SOLOSTAR & Sanofi-Aventis US LLC \\
\hline 00088250033 & APIDRA & Sanofi-Aventis US LLC \\
\hline 00088250052 & APIDRA & Sanofi-Aventis US LLC \\
\hline 00088250205 & APIDRA SOLOSTAR & Sanofi-Aventis US LLC \\
\hline 00169001771 & NOVOLIN $70 / 30$ & Novo Nordisk Inc \\
\hline 00169004471 & NOVOLIN R & Novo Nordisk Inc \\
\hline 00169004571 & NOVOLIN N & Novo Nordisk Inc \\
\hline 00169007011 & VELOSULIN BR & Novo Nordisk Inc \\
\hline 00169010001 & INSULIN PURIFIED & Novo Nordisk Inc \\
\hline 00169011101 & VELOSULIN BR & Novo Nordisk Inc \\
\hline 00169020001 & INSULIN PURIFIED & Novo Nordisk Inc \\
\hline 00169022201 & INSULATARD HUMAN INSULIN & Novo Nordisk Inc \\
\hline 00169030001 & INSULIN PURIFIED & Novo Nordisk Inc \\
\hline 00169033301 & MIXTARD HUMAN INSULIN 70/30 & Novo Nordisk Inc \\
\hline
\end{tabular}




\begin{tabular}{|c|c|c|}
\hline National Drug Code (NDC) & Proprietary Name & Manufacturer \\
\hline 00169183302 & RELION/NOVOLIN R & Novo Nordisk Inc \\
\hline 00169183311 & NOVOLIN R & Novo Nordisk Inc \\
\hline 00169183317 & NOVOLIN R PENFILL & Novo Nordisk Inc \\
\hline 00169183318 & RELION/NOVOLIN R & Novo Nordisk Inc \\
\hline 00169183402 & RELION/NOVOLIN N & Novo Nordisk Inc \\
\hline 00169183411 & NOVOLIN N & Novo Nordisk Inc \\
\hline 00169183417 & NOVOLIN N PENFILL & Novo Nordisk Inc \\
\hline 00169183418 & RELION/NOVOLIN N & Novo Nordisk Inc \\
\hline 00169183511 & NOVOLIN L & Novo Nordisk Inc \\
\hline 00169183702 & RELION/NOVOLIN 70/30 & Novo Nordisk Inc \\
\hline 00169183711 & NOVOLIN 70/30 & Novo Nordisk Inc \\
\hline 00169183717 & NOVOLIN 70/30 PENFILL & Novo Nordisk Inc \\
\hline 00169183718 & RELION/NOVOLIN 70/30 & Novo Nordisk Inc \\
\hline 00169231321 & NOVOLIN R INNOLET & Novo Nordisk Inc \\
\hline 00169231421 & NOVOLIN N INNOLET & Novo Nordisk Inc \\
\hline 00169231721 & NOVOLIN 70/30 INNOLET & Novo Nordisk Inc \\
\hline 00169244010 & INSULIN PURIFIED REGULAR PORK & Novo Nordisk Inc \\
\hline 00169244210 & INSULIN PURIFIED LENTE PORK & Novo Nordisk Inc \\
\hline 00169244710 & INSULIN PURIFIED NPH PORK & Novo Nordisk Inc \\
\hline 00169255013 & TRESIBA & Novo Nordisk Inc \\
\hline 00169266015 & TRESIBA & Novo Nordisk Inc \\
\hline 00169330312 & NOVOLOG & Novo Nordisk Inc \\
\hline 00169347318 & NOVOLIN R PENFILL & Novo Nordisk Inc \\
\hline 00169347418 & NOVOLIN N PENFILL & Novo Nordisk Inc \\
\hline 00169347718 & NOVOLIN 70/30 PENFILL & Novo Nordisk Inc \\
\hline 00169351215 & INSULIN STANDARD REGULAR & Novo Nordisk Inc \\
\hline 00169352215 & INSULIN STANDARD NPH & Novo Nordisk Inc \\
\hline 00169352815 & INSULIN STANDARD LENTE & Novo Nordisk Inc \\
\hline 00169355215 & INSULIN STANDARD SEMILENTE & Novo Nordisk Inc \\
\hline 00169357215 & INSULIN STANDARD ULTRALENTE & Novo Nordisk Inc \\
\hline 00169368213 & NOVOLOG MIX 70/30 & Novo Nordisk Inc \\
\hline 00169368512 & NOVOLOG MIX 70/30 & Novo Nordisk Inc \\
\hline 00169368712 & LEVEMIR & Novo Nordisk Inc \\
\hline 00169369619 & NOVOLOG MIX 70/30 & Novo Nordisk Inc \\
\hline 00169633910 & NOVOLOG FLEXPEN & Novo Nordisk Inc \\
\hline 00169643810 & LEVEMIR FLEXTOUCH & Novo Nordisk Inc \\
\hline 00169643910 & LEVEMIR & Novo Nordisk Inc \\
\hline 00169750111 & NOVOLOG & Novo Nordisk Inc \\
\hline 00403296118 & HUMULIN N & Compumed Pharmaceuticals Inc \\
\hline 00403344918 & HUMULIN R & Compumed Pharmaceuticals Inc \\
\hline 23490668700 & INSULIN HUMAN REGULAR & Palmetto State Pharmaceuticals \\
\hline 35356010200 & HUMALOG & Quality Care Products LLC \\
\hline 49999099310 & HUMULIN & Quality Care Products LLC \\
\hline 49999099410 & LANTUS & Quality Care Products LLC \\
\hline 54569165101 & ILETIN NPH I & A-S Medication Solutions LLC \\
\hline 54569165102 & ILETIN NPH I & A-S Medication Solutions LLC \\
\hline 54569165200 & ILETIN II REG. PORK & A-S Medication Solutions LLC \\
\hline 54569165202 & ILETIN II REG. PORK & A-S Medication Solutions LLC \\
\hline 54569231800 & HUMULIN N & A-S Medication Solutions LLC \\
\hline 54569231801 & HUMULIN N & A-S Medication Solutions LLC \\
\hline
\end{tabular}




\begin{tabular}{|c|c|c|}
\hline National Drug Code (NDC) & Proprietary Name & Manufacturer \\
\hline 54569231900 & "HUMULIN R & A-S Medication Solutions LLC \\
\hline 54569231901 & HUMULIN R & A-S Medication Solutions LLC \\
\hline 54569255700 & HUMULIN L & A-S Medication Solutions LLC \\
\hline 54569255701 & HUMULIN L & A-S Medication Solutions LLC \\
\hline 54569281600 & INSULIN PURIFIED LENTE PORK & A-S Medication Solutions LLC \\
\hline 54569281700 & INSULIN PURIFIED REGULAR PORK & A-S Medication Solutions LLC \\
\hline 54569289100 & ILETIN PORK NPH & A-S Medication Solutions LLC \\
\hline 54569289101 & ILETIN PORK NPH & A-S Medication Solutions LLC \\
\hline 54569291800 & NOVOLIN 70/30 & A-S Medication Solutions LLC \\
\hline 54569291801 & NOVOLIN 70/30 & A-S Medication Solutions LLC \\
\hline 54569291802 & NOVOLIN 70/30 & A-S Medication Solutions LLC \\
\hline 54569295100 & ILETIN REGULAR I & A-S Medication Solutions LLC \\
\hline 54569295101 & ILETIN REGULAR I & A-S Medication Solutions LLC \\
\hline 54569346700 & HUMULIN 70/30 & A-S Medication Solutions LLC \\
\hline 54569346701 & HUMULIN 70/30 & A-S Medication Solutions LLC \\
\hline 54569383300 & NOVOLIN R & A-S Medication Solutions LLC \\
\hline 54569383301 & NOVOLIN R & A-S Medication Solutions LLC \\
\hline 54569383302 & NOVOLIN R & A-S Medication Solutions LLC \\
\hline 54569383400 & NOVOLIN L & A-S Medication Solutions LLC \\
\hline 54569383401 & NOVOLIN L & A-S Medication Solutions LLC \\
\hline 54569383500 & NOVOLIN N & A-S Medication Solutions LLC \\
\hline 54569383501 & NOVOLIN N & A-S Medication Solutions LLC \\
\hline 54569383502 & NOVOLIN N & A-S Medication Solutions LLC \\
\hline 54569532100 & HUMALOG MIX 75/25 & A-S Medication Solutions LLC \\
\hline 54569560500 & LANTUS & A-S Medication Solutions LLC \\
\hline 54569630000 & LEVEMIR & A-S Medication Solutions LLC \\
\hline 54569630100 & LEVEMIR & A-S Medication Solutions LLC \\
\hline 54569630101 & LEVEMIR & A-S Medication Solutions LLC \\
\hline 54569643500 & HUMALOG & A-S Medication Solutions LLC \\
\hline 54569646200 & LANTUS SOLOSTAR & A-S Medication Solutions LLC \\
\hline 54569646201 & LANTUS SOLOSTAR & A-S Medication Solutions LLC \\
\hline 54569657000 & LEVEMIR FLEXTOUCH & A-S Medication Solutions LLC \\
\hline 54569658400 & NOVOLOG & A-S Medication Solutions LLC \\
\hline 54569658500 & HUMALOG & A-S Medication Solutions LLC \\
\hline 54569658600 & NOVOLOG & A-S Medication Solutions LLC \\
\hline 54569658700 & NOVOLOG FLEXPEN & A-S Medication Solutions LLC \\
\hline 54868011200 & LEVEMIR & Physicians Total Care \\
\hline 54868142801 & ILETIN NPH I & Physicians Total Care \\
\hline 54868142901 & HUMULIN N & Physicians Total Care \\
\hline 54868208901 & ILETIN REGULAR I & Physicians Total Care \\
\hline 54868238001 & NOVOLIN N & Physicians Total Care \\
\hline 54868274600 & HUMULIN 70/30 & Physicians Total Care \\
\hline 54868277700 & NOVOLOG & Physicians Total Care \\
\hline 54868347400 & NOVOLIN 70/30 & Physicians Total Care \\
\hline 54868359800 & NOVOLIN R & Physicians Total Care \\
\hline 54868361900 & HUMULIN R & Physicians Total Care \\
\hline 54868438100 & HUMALOG MIX 75/25 & Physicians Total Care \\
\hline 54868462600 & LANTUS & Physicians Total Care \\
\hline 54868510800 & HUMALOG & Physicians Total Care \\
\hline 54868520100 & NOVOLOG MIX 70/30 & Physicians Total Care \\
\hline
\end{tabular}




\begin{tabular}{|c|c|c|}
\hline National Drug Code (NDC) & Proprietary Name & Manufacturer \\
\hline 54868532700 & NOVOLOG MIX 70/30 & Physicians Total Care \\
\hline 54868532701 & NOVOLOG MIX 70/30 & Physicians Total Care \\
\hline 54868576500 & LANTUS & Physicians Total Care \\
\hline 54868582400 & HUMULIN 50/50 & Physicians Total Care \\
\hline 54868583600 & HUMALOG & Physicians Total Care \\
\hline 54868588300 & LEVEMIR & Physicians Total Care \\
\hline 54868589900 & HUMALOG PEN & Physicians Total Care \\
\hline 54868605400 & NOVOLOG FLEXPEN & Physicians Total Care \\
\hline 54868623100 & LANTUS SOLOSTAR & Physicians Total Care \\
\hline 55045350601 & HUMULIN R & Dispensing Solutions Inc \\
\hline 55045350801 & NOVOLIN 70/30 & Dispensing Solutions Inc \\
\hline 55045360201 & HUMALOG & Dispensing Solutions Inc \\
\hline 55045362401 & HUMULIN 70/30 & Dispensing Solutions Inc \\
\hline 55045368501 & LANTUS & Dispensing Solutions Inc \\
\hline 58016478801 & HUMULIN N & Southwood Pharm Inc \\
\hline 59060183302 & NOVOLIN R & Novo Nordisk Inc \\
\hline 59060183402 & NOVOLIN N & Novo Nordisk Inc \\
\hline 59060183702 & NOVOLIN $70 / 30$ & Novo Nordisk Inc \\
\hline 59060231404 & RELION NOVOLIN N INNOLET & Novo Nordisk Inc \\
\hline 59060231704 & RELION NOVOLIN 70/30 INNOLET & Novo Nordisk Inc \\
\hline 66143751005 & LISPRO-PFC & Midwest IV \\
\hline 68115070905 & NOVOLIN R PENFILL & Dispensexpress Inc \\
\hline 68115072810 & HUMULIN R & Dispensexpress Inc \\
\hline 68115072905 & HUMULIN N PEN & Dispensexpress Inc \\
\hline 68115074610 & HUMALOG & Dispensexpress Inc \\
\hline 68115083910 & LANTUS & Dispensexpress Inc \\
\hline 68258598301 & HUMALOG MIX $75 / 25$ & Dispensing Solutions Inc \\
\hline 68258889903 & NOVOLOG FLEXPEN & Dispensing Solutions Inc \\
\hline 68258892703 & LEVEMIR & Dispensing Solutions Inc \\
\hline 68258892803 & NOVOLOG & Dispensing Solutions Inc \\
\hline 68258893001 & NOVOLOG MIX 70/30 & Dispensing Solutions Inc \\
\hline 68258893103 & LANTUS SOLOSTAR & Dispensing Solutions Inc \\
\hline 68258896701 & NOVOLOG & Dispensing Solutions Inc \\
\hline 68258897701 & LEVEMIR & Dispensing Solutions Inc \\
\hline 68258898501 & HUMULIN N & Dispensing Solutions Inc \\
\hline 68258898601 & NOVOLIN N & Dispensing Solutions Inc \\
\hline
\end{tabular}


Table 10: Insulin Combinations

\begin{tabular}{lcc} 
Combinations & Prescription Claims & Percentage of Claims \\
\hline \hline Bolus Only & $2,672,920$ & 9.24 \\
Basal Only & $5,851,299$ & 20.23 \\
Both & $17,878,294$ & 61.81 \\
Other & $2,521,207$ & 8.72 \\
\hline Total & $28,923,720$ & 100
\end{tabular}

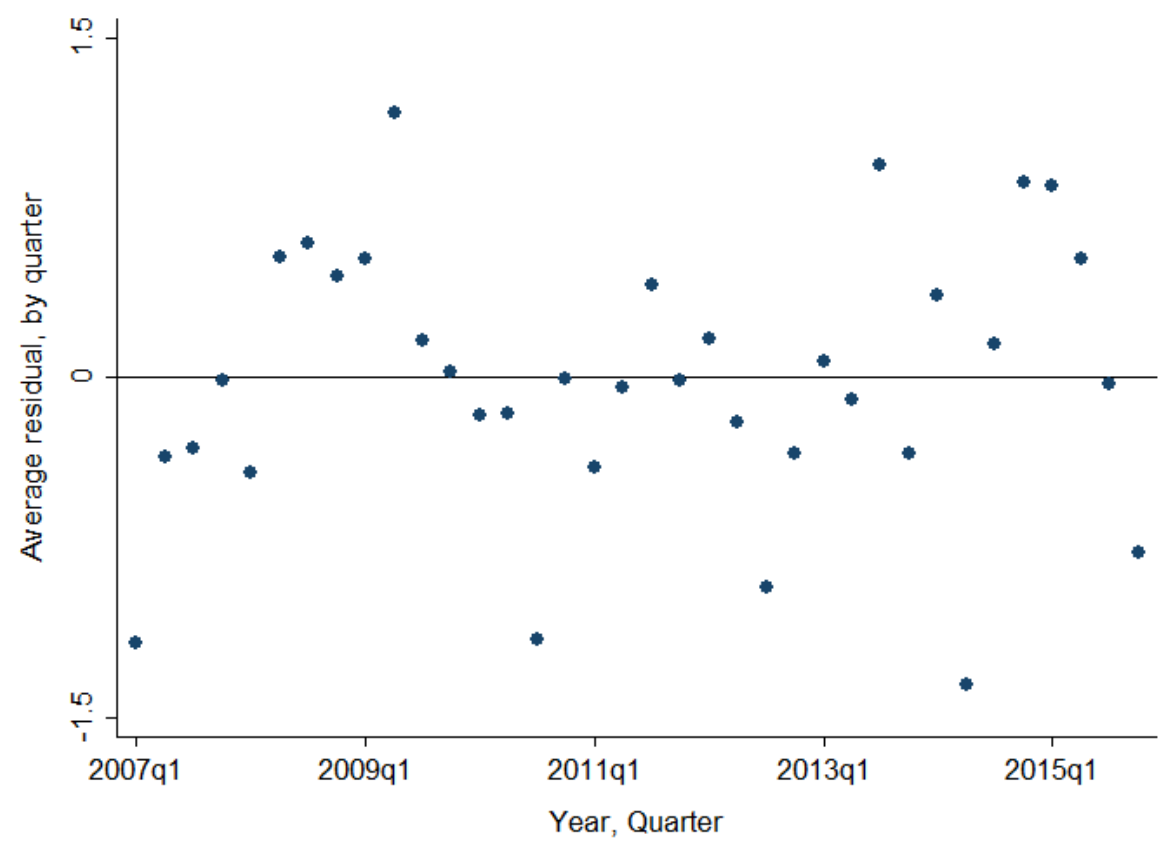

Figure 7: Average Residuals over Time 
Table 11: Price Effects using Pre- and Post-ACA Time Trends

\begin{tabular}{|c|c|c|}
\hline & $\begin{array}{c}(1) \\
\text { Original Time Trends }\end{array}$ & $\begin{array}{c}(2) \\
\text { ACA Time Trends }\end{array}$ \\
\hline \multicolumn{3}{|l|}{ Phase 3 Shocks } \\
\hline $1^{\text {st }}$ Pipeline Shock $t$ & $\begin{array}{l}-0.726 \\
(0.795)\end{array}$ & $\begin{array}{c}2.405^{* * *} \\
(0.473)\end{array}$ \\
\hline $2^{\text {nd }}$ Pipeline Shock $t$ & $\begin{array}{l}-1.147 \\
(0.912)\end{array}$ & $\begin{array}{c}-3.304^{* * * *} \\
(1.081)\end{array}$ \\
\hline $3^{r d}$ Pipeline Shock $t$ & $\begin{array}{l}2.285^{* *} \\
(1.053)\end{array}$ & $\begin{array}{c}1.527 \\
(0.952)\end{array}$ \\
\hline $4^{t h}$ Pipeline Shock $t$ & $\begin{array}{c}2.263^{* *} \\
(1.142)\end{array}$ & $\begin{array}{c}3.433^{* * *} \\
(1.041)\end{array}$ \\
\hline Time & $\begin{array}{c}0.715^{* * *} \\
(0.0957)\end{array}$ & \\
\hline $\operatorname{Time}^{2}$ & $\begin{array}{l}0.0323^{* * *} \\
(0.00636)\end{array}$ & \\
\hline pre_aca & & $\begin{array}{c}0.214^{* * *} \\
(0.0502)\end{array}$ \\
\hline post_aca & & $\begin{array}{c}1.879^{* * *} \\
(0.130)\end{array}$ \\
\hline Quarter 2 & $\begin{array}{l}-0.643 \\
(0.455)\end{array}$ & $\begin{array}{c}-0.896^{*} \\
(0.468)\end{array}$ \\
\hline Quarter 3 & $\begin{array}{l}-0.278 \\
(0.492)\end{array}$ & $\begin{array}{l}0.0643 \\
(0.493)\end{array}$ \\
\hline Quarter 4 & $\begin{array}{l}-0.412 \\
(0.516)\end{array}$ & $\begin{array}{l}0.0656 \\
(0.491)\end{array}$ \\
\hline \multicolumn{3}{|l|}{ Health Plan Type } \\
\hline Exclusive Provider Organization & $\begin{array}{c}-3.436^{* * *} \\
(0.308)\end{array}$ & $\begin{array}{c}-3.362^{* * *} \\
(0.311)\end{array}$ \\
\hline Health Maintenance Organization & $\begin{array}{c}-6.775^{* * *} \\
(0.307)\end{array}$ & $\begin{array}{c}-6.822^{* * *} \\
(0.307)\end{array}$ \\
\hline Non-capitated Point of Service (POS) & $\begin{array}{c}-3.508^{* * *} \\
(0.301)\end{array}$ & $\begin{array}{c}-3.542^{* * *} \\
(0.299)\end{array}$ \\
\hline Preferred Provider Organization & $\begin{array}{c}-4.923^{* * * *} \\
(0.238)\end{array}$ & $\begin{array}{c}-4.964^{* * * *} \\
(0.238)\end{array}$ \\
\hline Capitated or Partially-capitated POS & $\begin{array}{c}-9.680^{* * *} \\
(0.553)\end{array}$ & $\begin{array}{c}-9.704^{* * *} \\
(0.553)\end{array}$ \\
\hline Consumer Driven Health Plan & $\begin{array}{c}-7.624^{* * *} \\
(0.306)\end{array}$ & $\begin{array}{c}-7.621^{* * *} \\
(0.307)\end{array}$ \\
\hline High Deductible Health Plan & $\begin{array}{c}-7.007^{* * *} \\
(0.319)\end{array}$ & $\begin{array}{c}-7.024^{* * *} \\
(0.319)\end{array}$ \\
\hline Constant & $\begin{array}{c}22.80^{* * *} \\
(0.758)\end{array}$ & $\begin{array}{c}19.45^{* * *} \\
(0.636)\end{array}$ \\
\hline R-squared & 0.222 & 0.222 \\
\hline Observations & $27,359,428$ & $27,359,428$ \\
\hline Number of drugs & 122 & 122 \\
\hline
\end{tabular}

